\title{
Corrosion of Steel Bars Embedded in Fibre Reinforced Concrete Under Chloride Attack: State-of-the-Art
}

\author{
Carlos G. Berrocal ${ }^{\mathrm{a}, \mathrm{b}, *}$, Karin Lundgren ${ }^{\mathrm{a}}$, Ingemar Löfgren ${ }^{\mathrm{a}, \mathrm{b}}$ \\ ${ }^{a}$ Chalmers University of Technology, SE-41296, Göteborg, Sweden \\ ${ }^{b}$ Thomas Concrete Group AB, Södra Vägen 28, 41254 Göteborg, Sweden
}

\begin{abstract}
This paper summarises the influence of steel fibres on the main parameters governing the corrosion of conventional reinforcement. The ability of fibres to suppress crack width openings has proven to decrease permeation in cracked concrete while chloride diffusion, in uncracked concrete, seems to remain unaffected by the addition of fibres. Steel fibres in concrete are considered to be insulated by a high impedance passive layer. However, they will become conductive if corrosion initiates. Although low carbon steel fibres may suffer severe corrosion when located near the concrete surface or bridging the cracks, embedded fibres will remain free of corrosion despite high chloride contents. Published experimental observations indicate that fibres had little influence on the corrosion rates of rebar. The present literature review reveals that moderately improved corrosion resistance of rebars, achieved by adding steel fibres, is mainly attributed to a lower ingress of chlorides due to arrested crack growth.
\end{abstract}

Keywords: Fibre Reinforcement, Chloride, Corrosion, Reinforcement, Permeability, Durability

\section{Introduction}

Under most conditions, well-designed and executed reinforced concrete structures present good durability. The high alkalinity of the pore solution of the concrete provides the ideal environment whereby embedded reinforcement can be protected from corrosion. Under these conditions, a very thin, dense and stable iron-oxide film is formed. This film, often referred to as passive layer, greatly reduces the ion mobility between the steel and surrounding concrete; thus, the rate of corrosion drastically drops and becomes negligible [1]. Nevertheless, corrosion remains one of the major problems affecting reinforced concrete structures 2 . Corrosion damage on reinforcement and prestressing steel has been identified as the primary cause of a significant number of structural failures over the past centuries and represent a high cost to society in terms of repairs, monitoring and replacement of structures [3.

\footnotetext{
${ }^{*}$ Corresponding author. Tel: +46 317722262

Email address: carlos.gil@chalmers.se (Carlos G. Berrocal )
}

Preprint submitted to Cement and Concrete Research
The most common causes of corrosion initiation in reinforcement are: (i) an ingress of carbon dioxide from the atmosphere decreasing the alkalinity of the pore solution; and (ii) the local depassivation of steel due to the presence of chlorides at the reinforcement level 44. The latter occurs when sufficient chlorides build up at the reinforcement surface, i.e. the chloride concentration exceeds a certain limit known as the critical chloride content [5]. This tends to cause localised breakdown of the passive film, a phenomenon termed pitting corrosion [6], provided enough water and oxygen are available at the surface of the reinforcement. This phenomenon may result in a serious local loss of the cross section of the bars in the affected regions while the surrounding regions remain virtually unaffected.

Several reports showed that water permeation in cracked concrete rapidly increases as the crack width grows larger than a certain threshold, e.g. [7. 8. Crack width has also been identified as one of the primary factors influencing the autogenous healing of cracks in concrete 9. Hence, when cracks exceed a certain threshold, they play an essential role in the transport of aggressive agents and

May 11, 2017 
is therefore imperative to the service life of concrete structures to effectively control these cracks. Current regulations and design codes define permissible crack widths, i.e. maximum allowed crack widths, based on the exposure conditions, as a way of ensuring the durability of reinforced concrete structures, cf. [10, 11. Even though several authors have investigated the impact of cracks on the initiation and propagation of corrosion, e.g. [12, 13, 14, [15, 16, 17, [18, [19, 20, 21, 22, 23, the effect of cracks on durability is still debated. The only consensus amongst researchers is that if the cracks were to exceed a certain size, i.e. are too large, they will negatively impact durability. However, according to a study carried out by Otieno et al. 20, it is not possible to determine a universal crack width limit.

The advantages of using fibres in structural members have been demonstrated in a number of research investigations, e.g. [24, 25]; despite this fact, their use in structural applications is still limited. One explanation is the lack of codes and regulations, but also because of the fibres are not aligned in the direction of the principal stress direction and the uncertainties in the distribution of the fibres throughout the cementitious matrix, which makes it unlikely that fibres will completely replace conventional reinforcement in large structural members 26]. In fact, fibres are predominantly used in pavements, industrial floors and slabs on grade to control crack width, mostly due to plastic and drying shrinkage 27, although they are also used for tunnel linings, as sprayed concrete and precast segmental linings. Nevertheless, closely spaced fibres can improve the toughness and tensile properties of concrete and significantly contribute to controlling and reducing crack widths. Besides, it has been found that steel fibres, in general, have a higher corrosion resistance than conventional reinforcement. For example, Raupach et al. 28] reported that fibres embedded in concrete show significantly higher critical chloride contents, (up to $4.7 \% \mathrm{Cl}^{-}$), although fibres located at the surface, at depths of up to $6 \mathrm{~mm}$, are susceptible to corrosion, see e.g. [29, 30, 31]. Therefore, it might be advantageous to use fibre reinforcement as a complement to traditional reinforcing bars to provide crack control mechanisms in civil engineering structures and get rid of congested reinforcement layouts often needed to meet the strict crack width limitations required in the current structural codes.

However, owing to the limited research and expe- rience available in this field, the use of steel fibres raises questions as to when they are used in combination with conventional reinforcement in chloride environments. Some of these questions are related to the influence the fibres may have with respect to chloride ingress and moisture transport. However, the main issue that has yet to be dealt with is if there is a risk of higher corrosion rates when conductive fibres are present in the concrete matrix. Another aspect, only mentioned a few times in the literature, is the potential ability of fibres to become sacrificial anodes, which raises questions regarding the risk of galvanic corrosion between fibres and conventional reinforcement bars.

Through an extensive review of the existing literature, the present study aims to investigate the influence of steel fibres on chloride induced corrosion of reinforcing bars embedded in concrete. Since the studies investigating corrosion of steel bars in fibre reinforced concrete are scarce, in first place, the effect of steel fibres on the most relevant parameters governing corrosion of reinforcement in concrete, including cracking, permeability, chloride ingress and resistivity, is analysed by examining published data from experimental investigations. Subsequently, the reported results from research studies combining steel fibre and conventional reinforcement have been compared. Based on that, the potential benefits and challenges of using steel fibres in combination with reinforcing bars in concrete structures exposed to chlorides are discussed. Moreover, the literature review will highlight some key aspects of the combined use of steel bars and fibres that have yet to be fully understood and that may require further research.

\section{Influence of Fibres on Cracking of Con- crete}

Since the first studies on steel fibre reinforced concrete (SFRC) by Romualdi and his colleagues (see e.g. 32] ) in the early 1960's, a significant amount of research has been carried out to gain a deeper understanding of the mechanical properties and the fracture process of this material. According to Naaman and Reinhardt [33], the tensile behaviour of cementitious materials may be classified as either strain softening (a quasi-brittle material) or pseudo-strain-hardening. Strain softening materials present localised cracks and loss of stress once the matrix cracks. Conversely, pseudo-strain hardening materials exhibit multiple-cracking up to 
the post-cracking strength, which is higher than the cracking strength. This behaviour is schematically represented in Fig. 1 .

The need for high fibre volume fractions and relatively high-performance concretes in order to obtain a pseudo-strain hardening behaviour, added to the low efficiency of fibres caused by their random position and orientation throughout the concrete matrix, today poses an important impediment to the total replacement of conventional reinforcing bars in large structural elements. However, fibres in combination with steel bars could be used to improve the mechanical response of reinforced concrete elements.

Over the past years, several authors have investigated this possibility by studying the influence of fibre reinforcement on the mechanical response of reinforced concrete elements subjected to pure tension, see e.g. [35, 36, 37, 38, 39, 40, 41. The general agreement is that specimens containing steel fibres exhibit increased tension stiffening, even at large deformations, and transverse cracks are narrower and more closely spaced than in plain concrete specimens. The typical crack patterns observed in pure tension tests are illustrated in Fig. 2 .

In a study by Jansson et al. 42, pull-out tests with short embedment length were carried out to investigate the influence of steel fibres on reinforcement bond for fibre contents up to $1.0 \%$ by volume. Although the pre-peak behaviour seemed to remain unaffected by the presence of fibres, after cracking fibres had provided a confinement effect comparable to that provided by stirrups. Fibres effectively controlled the splitting crack growth thereby changing the failure mode from splitting to pulling out of the rebar.

In a recent thesis from Denmark Technical University, Larusson 43 investigated the bond slip and tension stiffening mechanisms in reinforced tie elements made of Engineering Cementitious Composites (ECC) using 2\% vol. Poly-Vinyl Alcohol (PVA) fibres. Using an innovative test setup with partially exposed reinforcement, in combination with high definition Digital Image Correlation (DIC) techniques, the formation and propagation of cracks at the interface between the reinforcement and concrete matrix were monitored and quantified at a micro-scale. The results showed that ECC elements consistently presented multiple cracking with considerably smaller crack widths as opposed to RC where a wide localized crack tended to form. Furthermore, the slip and opening displacements mea- sured at the interface revealed that bond degradation was significantly decreased for ECC members compared to RC ones.

In another study by Otsuka et al. 44, the formation of internal cracks around a ribbed bar embedded in a notched prism was investigated. The authors of the study performed their experiments using a singular detection technique consisting in $\mathrm{X}$-ray radiographing of the specimen after it had been injected with a contrast medium. The observations based on their tests showed that after the formation of an initial crack at the notch, the width of the primary crack did not extend but a number of internal cracks accumulated even after the reinforcement had yielded. These cracks, mostly growing from the lugs of the rebar, presented a truncated cone shape with very narrow widths at the concrete surface and wider regions of micro-cracks gathered at the reinforcement level. This finding was in accordance with those by Fantilli et al. 34 who studied the crack profile in tension members made of RC, FRCC and HPFRCC. They concluded that, when fibres are added to $\mathrm{RC}$ tie members to provide higher fracture energy, cracks will be narrower and the crack widths on the interface between the steel rebar and concrete will be larger than on the surface, even after yielding of the rebar.

The addition of steel fibres to concrete may therefore influence not only the width of transverse cracks but also a number of factors which have been considered to play a role for corrosion of conventional reinforcement. Arya and Ofori-Darko 45 investigated the effect of crack spacing on corrosion and concluded that reduced crack spacings would result in greater amounts of corrosion. Hence, fibres would have a negative impact since cracks form more closely spaced in FRC elements. On the other hand, an increased stress level at the reinforcement was suggested by Yoon et al. 15] and Tammo [46] to be a factor leading to higher rates of corrosion. Based on that, fibre reinforcement would be beneficial since crack bridging fibres contribute to transfer part of the load through the cracks, thereby alleviating the stress demands at the reinforcing bars. Another aspect in which fibres could play a beneficial role is the suppression of splitting cracks, since such cracks, running parallel to the reinforcement, have been regarded as specially harmful with respect to corrosion of reinforcement [47].

As discussed by Angst et al. in 48 the condition of the interfacial transition zone (ITZ), and particularly the existence of local defects such as 


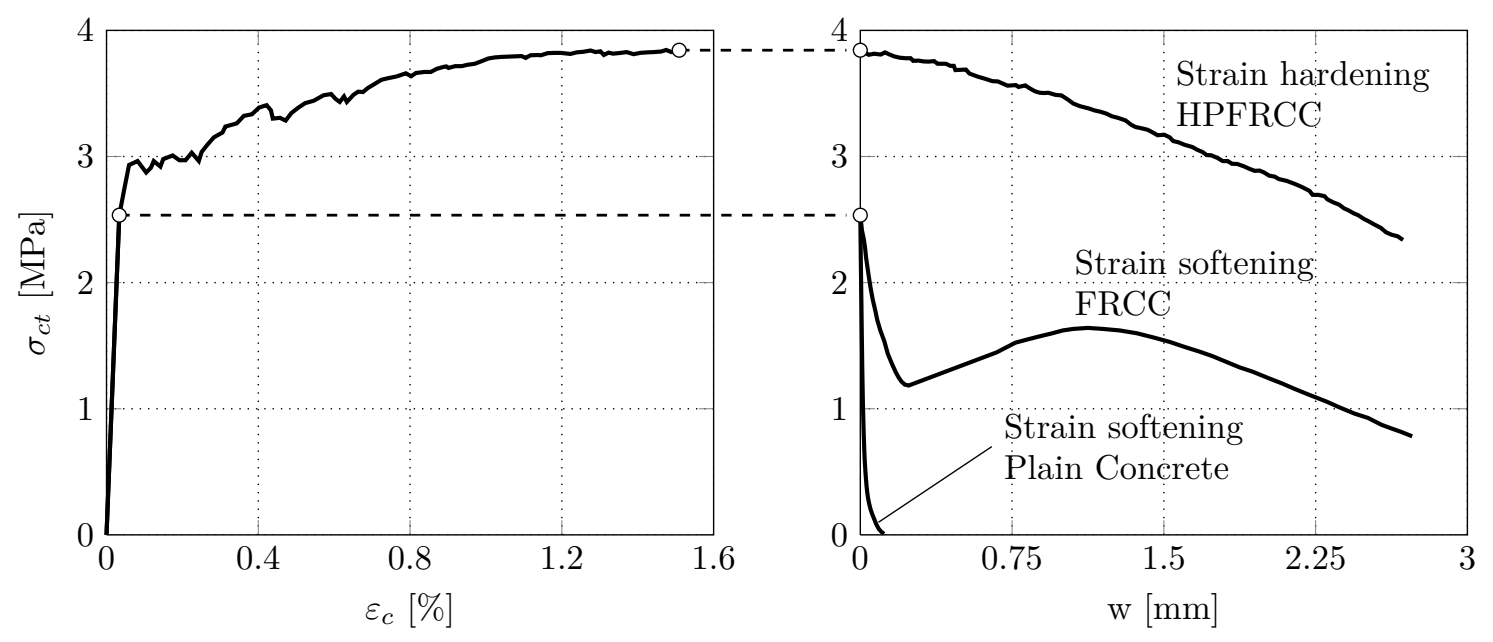

Figure 1: Tensile strength classification of cementitious materials, adapted from 34

air voids, gaps or cracks at the steel-concrete interface, is a decisive factor for corrosion onset. This is in agreement with the results of an investigation by Pease et al. [49], in which the authors used a novel test setup consisting in an instrumented rebar to assess the corrosion of cracked reinforced concrete. They observed that damage at the interface between concrete and steel, produced during mechanical loading, facilitated the ingress of chlorides along the rebar thereby increasing the areas on the steel surface where corrosion was thermodynamically favoured. Although these areas were found to be significantly larger than the actual size of the formed anodes, indicating that anodic regions may protect electronically connected neighbouring regions, they concluded that damage at the steelconcrete interface may be related to an increased risk of corrosion and is likely more relevant to reinforcement corrosion than surface crack width.

This hypothesis was further investigated by Michel et al. in [50]. In that study the authors used the instrumented rebar mentioned earlier to monitor the corrosion along a reinforcement bar embedded in a concrete member subjected to bending cracks and employed a FEM model to estimate the steel-concrete interface degradation in terms of slip and separation. Their results showed a very good agreement between the regions where electrochemical measurements indicated active corrosion and the simulated extent of interfacial separation. Their conclusion was that the condition of the concretereinforcement interface can be used as a reliable indicator to quantify the impact of load-induced cracks on the risk of corrosion initiation. Based on that, experimental observations in which fibre reinforcement provided mechanisms to limit the steelconcrete separation along the rebar suggest that the addition of fibres might reduce the risk of corrosion initiation in the reinforcing bars.

Another important factor to consider during the corrosion propagation phase is the anode-tocathode area ratio, as discussed by Michel in [51]. For very small ratios of the anode-to-cathode areas, the overall amount of corrosion would be limited but the local corrosion current density would be very high, leading to important local loss of the steel cross-section. As the ratio between the anodic and cathodic areas increase, the current density would decrease locally but the total amount of corrosion would increase. According to Schießl and Raupach [17] and in line with the findings by Pease [52], in concrete elements with transverse cracks the preferred corrosion mechanism is macro-cell corrosion, with the anodic regions located at the surface of the rebar crossing the crack and the neighbouring regions of reinforcement embedded in uncracked concrete acting as cathodes. Therefore, the influence of fibre reinforcement is uncertain as the anodic area could be locally decreased at each crack by a reduced steel-concrete separation whereas an increased number of cracks could potentially lead to a larger number of anodes along the reinforcement surface. 

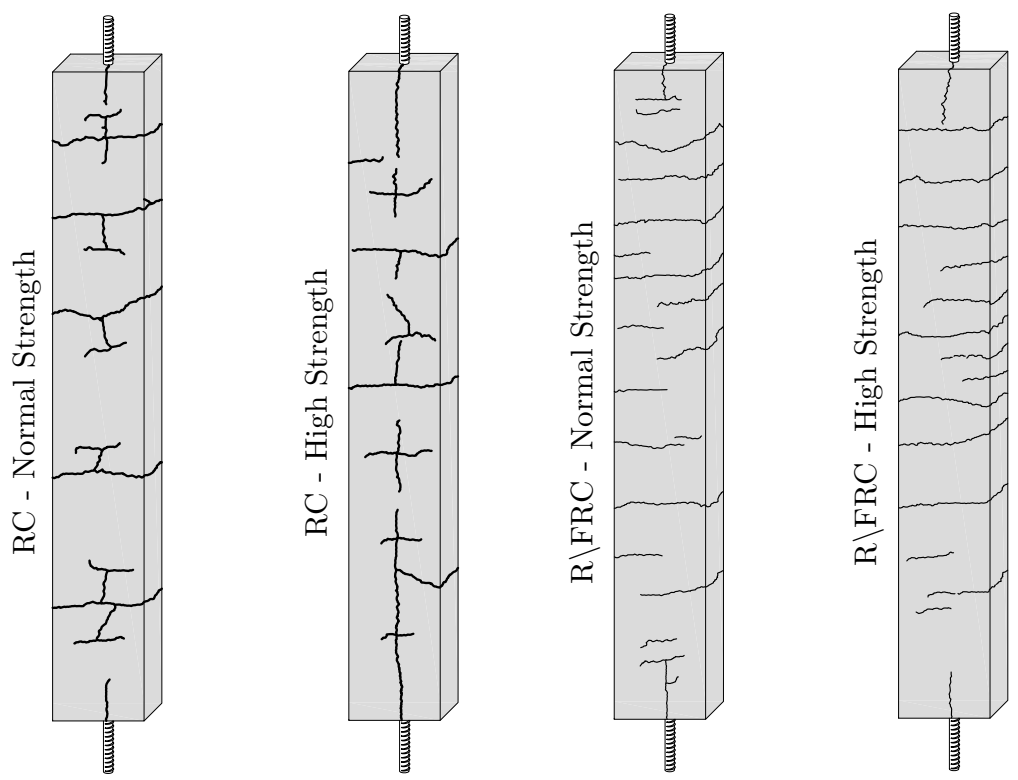

Figure 2: Typical crack pattern in tie elements, after 35.

\section{Influence of fibres on transport and elec- trical properties}

The phenomena causing degradation of reinforcement in concrete structures are largely dependent on the mechanisms that allow the ingress of water, oxygen and detrimental agents, such as chloride ions or $\mathrm{CO}_{2}$, as well as mechanisms that allow transfer of electrical current, to mention a few. The transport mechanisms can be roughly divided into transport in the bulk material vs. transport in micro- and macro-cracks. Transport in the bulk material can be further classified into four basic mechanisms: capillary suction, caused by capillary forces, sometimes also referred to as absorption; permeation, driven by a pressure gradient; diffusion, driven by a concentration gradient; and $m i$ gration, due to an electric potential gradient 3 .

The ingress of chloride ions, which can only penetrate concrete dissolved in pore water, is a complex phenomenon often involving different mechanisms. Depending on the exposure conditions, the transport of chloride ions may be governed by permeation, absorption, diffusion or a combination thereof. Permeation has a special interest in waterretaining and underwater structures but, as discussed later, when the crack width exceeds a certain threshold it becomes relevant for other structures as well. Absorption by capillary suction is important when concrete with a low degree of saturation is exposed to chloride solution, whereas diffusion is predominant when the concrete is fully saturated. Once the chloride ions have reached a concentration level high enough to break down the passive layer, the reinforcement will actively corrode, if there is sufficient oxygen available at the reinforcement surface. Corrosion can be seen as a sequence of electrochemical reactions occurring within the concrete, between the steel and the surrounding concrete. Therefore, the electrical properties of concrete are also of interest in order to control the rate at which corrosion proceeds. In this section, the influence of fibres on some of these properties is studied by reviewing the existing experimental results in the literature and disscussing the conclusions drawn from the respective studies.

\subsection{Permeation}

Permeation is considered one of the most important transport mechanisms in concrete that can be directly related to its durability $[53$. The word permeability is often used to refer to the general properties of a material in relation to all transport mechanisms whereas the term permeation is preferred to describe the penetration of a fluid through the pores 
of a material under a differential pressure. Nevertheless, the term "coefficient of permeability" will be used instead of the more accurate term "coefficient of permeation", as this is common practice 3. On the assumptions that (i) the fluid is incompressible and entirely viscous, (ii) the flow is laminar and has reached a steady state and (iii) the medium is fully saturated, the fluid flow through a porous medium can be described by Darcy's law 3.

$$
\frac{\mathrm{d} q}{\mathrm{~d} t}=\frac{K \cdot \Delta P \cdot A}{L \cdot \mu}
$$

where $d q / d t$ is the flow $\left(\mathrm{m}^{3} / \mathrm{s}\right), \mu$ is the fluid viscosity $\left(N \cdot s / m^{2}\right), K$ the intrinsic coefficient of permeability of the material $\left(\mathrm{m}^{2}\right), \Delta P$ the applied pressure difference $(\mathrm{Pa})$ and $A\left(\mathrm{~m}^{2}\right)$ and $L(\mathrm{~m})$ represent the cross-sectional area and length of the specimens, respectively. Permeation can be tested for any liquid, but the coefficient of permeability, sometimes referred as to hydraulic conductivity, is commonly measured for water. The coefficient of permeability is measured in $\mathrm{m} / \mathrm{s}$ and is connected to the intrinsic permeability by the equation $k=$ $K \cdot \rho \cdot g / \mu$, where $\rho$ is the density and $\mu$ represents the viscosity.

\section{The influence of crack width on permeation}

In uncracked concrete, permeation is attributed to the capillary porosity of the cement paste and decreases as the $w / c$ ratio decreases and the cement hydration proceeds. However, the presence of cracks in concrete can drastically alter the coefficient of permeability. This has been shown through experimental observations by several authors. Wang et al. 7] used a feedback controlled splitting test to induce cracks of desired width by indirect tension, using $25 \mathrm{~mm}$ thick specimens with a diameter of $100 \mathrm{~mm}$. After cracking, permeability tests were performed and results showed that the coefficient of permeability increased with increasing crack width except for very narrow cracks below 0.1 $\mathrm{mm}$ where scant variation in the permeability coefficient was observed. Using a similar setup to induce cracking, Aldea et al. [8] evaluated the relationship between water permeation and cracking including the influence of various material types (Normal vs. High Strength Concrete) and specimen thickness (25 vs $50 \mathrm{~mm}$ ). Results showed that crack recovery upon unloading for NSC compared to HSC decreased with increasing crack width, which was attributed to a less elastic NSC response due to higher tortuosity of the crack morphology. That fact resulted in higher permeability coefficients for NSC than for HSC for the same crack width whereas the specimen thickness was found to have little effect on permeation. In another study by Aldea et al. [54, the water flow in cracked concrete was investigated under loaded conditions for cracks induced in wedge-splitting test and tension-splitting test. The results were compared with analytical calculations from a model based on the Poiseuille law, often used in rock mechanics, to estimate the laminar flow between two parallel-sided plates, on which the flow is proportional to the cube of crack width, cf. [9]. Fig. 3 presents the influence of cracking on the water permeability coefficient as a function of the average crack width. It is noteworthy that the y-axis in Fig. 3 is in logarithmic scale, indicating a remarkable increase of the permeability coefficient of several orders of magnitude for crack widths of up to $0.4 \mathrm{~mm}$. Looking at these results it becomes clear that any measure adopted to preserve the low coefficient of permeability of sound concrete will potentially contribute to achieving structures of greater durability.

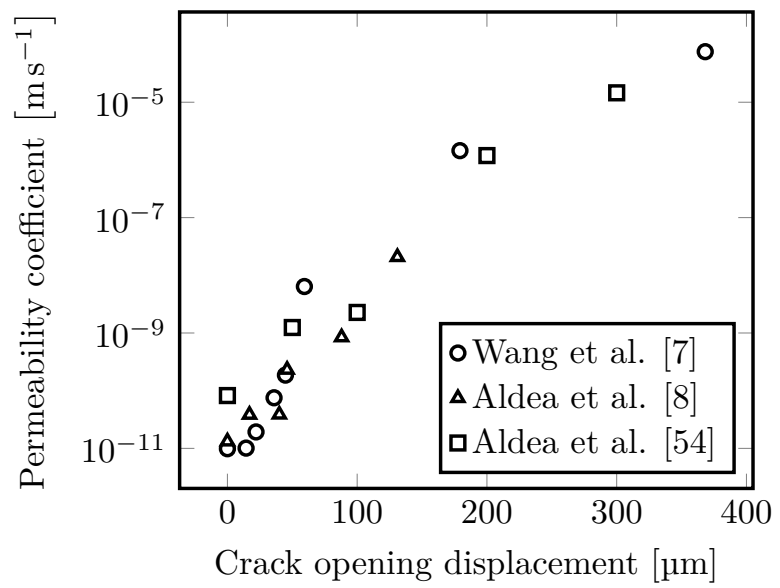

Figure 3: Influence of crack width on permeability coefficient of concrete, experimental results from [7, 8, 54]. Observed cracks propagated through the full depth of the specimen in the direction of the flow.

The influence of fibres on permeation of uncracked concrete

Although the main reason to add fibres is to provide crack control mechanisms, in fibre reinforced concrete elements fibres would also be present in 
uncracked regions. It is therefore important to investigate whether fibres could influence the properties of uncracked concrete in terms of permeation. Roque et al. 55 carried out permeability tests on uncracked concrete specimens containing different types of fibres. The results showed that fibres had little influence on the permeability coefficient. In particular, steel fibres showed a similar or slightly better performance compared with plain concrete specimens. In another study by Singh and Singhal [56], the authors investigated the influence of fibre dosage, aspect ratio and concrete age, on the permeability of uncracked $100 \mathrm{~mm}$ cube specimens with steel fibres alone. The results of their investigation are presented in Fig. 4, in which the addition of fibres slightly decreased the permeability coefficient of concrete - an effect that was enhanced for higher fibre dosages and lower aspect ratios. The authors suggested that this reduction was mainly attributed to the decrease of shrinkage cracks by the presence of fibres, although given the size of their specimens no significant shrinkage cracks would be expected. A more plausible explanation for the observed behaviour could be attributed to a reduction of the relative volume of cement paste by the addition of fibres. However, no information was available regarding how fibres were incorporated to the mix design.

\section{The influence of fibres on permeation of cracked concrete}

Taking advantage of the crack limiting effects of fibre reinforcement, several authors have investigated the influence of fibres on the coefficient of permeability of concrete, in cracked specimens. Rapoport et al. [57] used the test setup described in [7] to study the influence of steel fibres on the coefficient of permeability of cracked concrete for two different dosages, 0.5 and $1.0 \%$ vol. and for cracks ranging between 0 and $0.5 \mathrm{~mm}$. The results showed that steel macro-fibres may hinder the increase of crack induced permeability. They also found that a crack threshold exists below which permeation is insignificantly altered, which is in agreement with the value of $0.1 \mathrm{~mm}$ for plain concrete found in [8]. Charron et al. [58] investigated the permeability properties of an ultra-high performance fibre reinforced concrete (UHPFRC) with a $w / c$ ratio of 0.14 and a fibre dosage of $6 \%$ by volume. Cracking was induced in uniaxial tensile tests on prismatic specimens measuring $50 \times 200 \times 500 \mathrm{~mm}$. Permeation tests were carried out using glycol instead of water to prevent the reaction of the unhydrated cement and the consequent decrease in the coefficient of permeability, although the authors argued that this might have been more realistic. Considering a measurement basis of $100 \mathrm{~mm}$, an accumulated crack width was calculated from the remaining plastic strain after unloading. Their results also showed a lower increase in the permeability coefficient compared to normal concrete for increasing tensile deformations, especially for large strains. Similarly, an accumulated crack threshold for UHPFRC around $0.13 \mathrm{~mm}$ was reported, below which permeability remained unaffected.

Similar results as the previously mentioned regarding the permeability of cracked fibre reinforced concrete can be found in the investigations by Lepech and Li [59], who studied specimens made of engineered cementitious composite using PVA fibres, Tsukamoto 60] who examined the water flow through notched plates cracked in tension with and without fibre reinforcement for a variety of fibre types, and Tsukamoto and Wörner 61] who also investigated the influence of the aggregate sieve curve and the interaction with conventional reinforcement in notched plates. In the latter, it was observed that permeability decreased with increasing fibre dosages of up to $2.5 \%$ vol. and that higher dosages would produce a negative effect. They also concluded that fibres could provide a reduction in permeability additional to that achieved by conventional reinforcement. More recently, Lawler et al. 62, 63. evaluated the water permeability of fibre reinforced mortar and concrete subjected to tensile load. Fibre reinforcement included steel macro fibres and a blend of steel macro and PVA or steel micro fibres. By measuring the flow rate, their results showed that micro-cracks need to coalesce to form a localized crack ater which cracks need to be opened to a certain value before the flow rate becomes significant. In their experiments, they used $125 \times 100 \times 50 \mathrm{~mm}$ specimens but no major variation was registered in the water flow until the displacement reached approximately $0.1 \mathrm{~mm}$. Moreover, all fibre reinforced specimens exhibited higher water tightness than those without fibres. Fig. 5 shows the influence of fibre reinforcement on the permeability of cracked concrete in terms of the permeability coefficient as a function of the crack width Fig. $5 \mathrm{a}$ and the flow rate as a function of the displacement Fig. 5b 


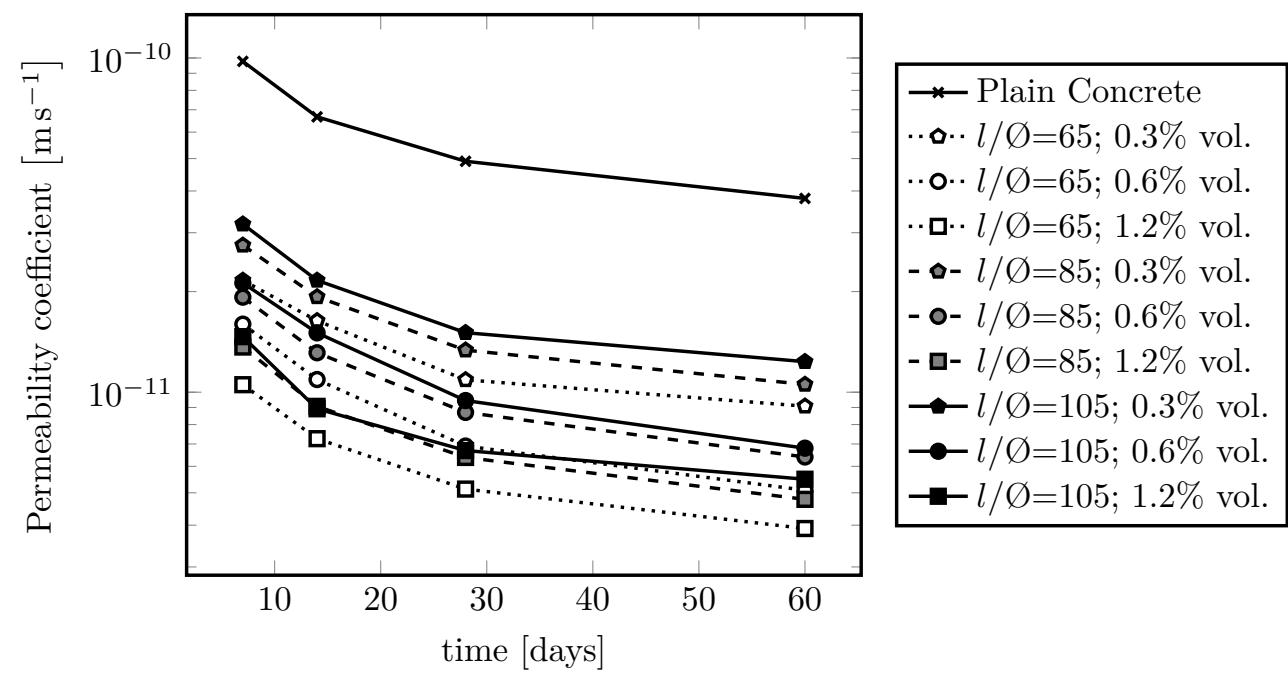

Figure 4: Influence of fibre dosage, aspect ratio and concrete's age on permeability coefficient, from [56]

\subsection{Chloride Diffusion}

Diffusion is the primary mechanism of chloride transport in concrete when the moisture condition in the pore system of the concrete is stable and no electric field is applied 64. Diffusion can be described as the movement of ions from the surface pores of the concrete, where they can be found in higher concentrations, towards the inner pores where the concentration is lower. The diffusion process in a semi-infinite medium for the onedimensional case can be mathematically expressed by the Fick's second law. A solution to that equation can be written in the following form [65]:

$$
C(x, t)=C_{s}\left[1-\operatorname{erf}\left(\frac{x}{2 \sqrt{D \cdot t}}\right)\right]
$$

where $D$ is the diffusion coefficient in $\left(\mathrm{m}^{2} / \mathrm{s}\right), t$ is the time of exposure in $(s)$, erf is the error function, and $C_{s}$ and $C(x, t)$ represent the chloride concentration at the concrete surface and at a depth $x$ after a time $t$, usually expressed in $\%$ by concrete weight. This expression, however, entails a number of assumptions. Firstly, Eq. (2) has been integrated assuming that the surface concentration is constant in time and that the initial concentration is zero for any point other than the surface $(C(x>0,0)=0)$. Additionally, the diffusion coefficient, $D$, does not vary in time and the material is considered homogeneous ( $D$ is kept constant along the thickness).

Several analytical models exist to predict the chloride ingress into concrete structures. Some of them are directly based on the Fick's second law solution shown in Eq. (2) while other more sophisticated models can account for the time dependency of the chloride surface concentration and/or diffusion coefficient. There are models capable of also taking into consideration the phenomenon of chloride binding. A discussion of the existing models whereby chloride ingress into concrete structures may be predicted can be found in 66. Nevertheless, most of these models are based on the Fick's law of diffusion and rely on the diffusion coefficient as a main parameter by which the chloride ingress into concrete structures may be assessed, which shows the importance of the diffusion mechanism and its evaluation.

In the mid-1980's, Mangat and Gurusamy 67. studied the influence of different types of steel fibres on chloride penetration. They used prismatic specimens measuring $100 \times 100 \times 500 \mathrm{~mm}$. Some specimens were kept uncracked whereas the rest were cracked with crack widths ranging from 0.07 to 1.08 $\mathrm{mm}$. Specimens were then divided and exposed to two different environments: a laboratory environment with a cyclic exposure into a sea water spray chamber and a natural environment subjected to tidal cycles at Aberdeen Beach. They found that fibres had an insignificant effect in uncracked concrete. For cracked FRC, cracks below $0.2 \mathrm{~mm}$ had a marginal impact on the chloride penetration but this became significant for cracks above $0.5 \mathrm{~mm}$. Roque et al. 55 analysed the chloride diffusion coefficient of hardened concrete for mixes with various types of fibre reinforcement. They performed 


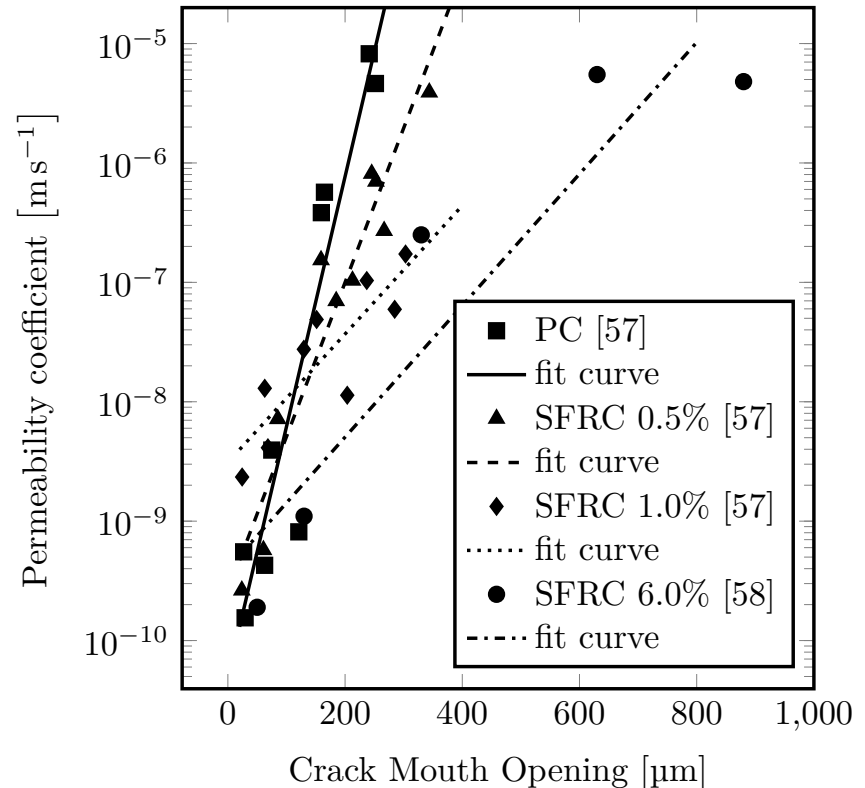

(a)

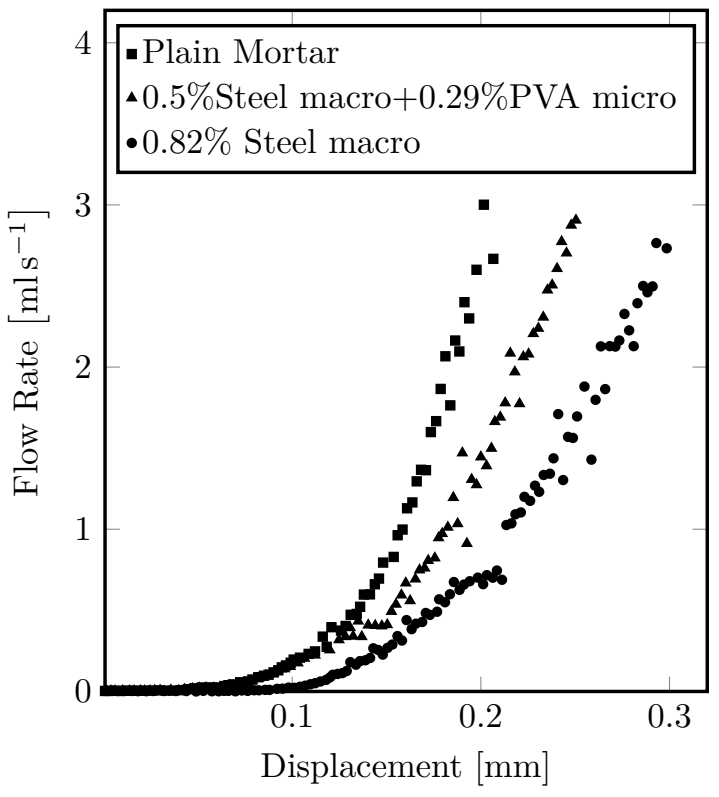

(b)

Figure 5: Influence of fibres on permeability of cracked concrete: (a) permeability coefficient as a function of crack width from [57. 58] and (b) flow rate as a function of displacement after [63. Fibre content is given in \% by volume. Observed cracks propagated through the full depth of the specimen in the direction of the flow.

bulk diffusion tests in accordance with NT Build 44368 after 365 days of exposure to chloride solution. They observed that fibre reinforced mixes exhibited lower rates of chloride diffusion compared to plain concrete and among the fibres used, although the reduction was generally small, the steel fibres showed the greatest resistance to chloride ingress. Although not discussed in [55], a possible explanation for these results could be attributed to the composition of the mixes in which the amount of coarse aggregate was reduced to accommodate the fibres. Since the steel fibres were added at $1 \%$ vol., the largest content among all the FRC mixes, a relatively higher cement to coarse aggregate ratio could explain the slightly reduced diffusion coefficient obtained.

This finding is in agreement with the results reported by Teruzzi et al. 69], who investigated the durability of steel fibre reinforced concrete mixes specifically tailored for applications where this material is widely used, i.e., industrial floors and precast elements. They performed several tests to compare the ingress of different aggressive agents into concrete with and without fibres and found no significant effects on chloride diffusion measured according to [70, among other indicators, attributable to the presence of fibres in concrete. They concluded that the interfacial zone around the fibres does not act as a preferential path for the penetration of detrimental agents. In a recent project carried out at the Chalmers University of Technology, Abrycki and Zajdzinski [71] assessed the chloride migration coefficient of concrete mixes with varying dosages of steel fibre reinforcement according to the setup described in NT Build 492 [72]. They found that adding steel fibres into concrete does not significantly alter the penetration of chloride ions into the concrete.

Other authors used the enhanced flowability of self-compacting concrete to offset the reduction in workability caused by the addition of fibres and studied its durability performance. Sánchez et al. [73] investigated several durability indicators including mercury intrusion porosity, chloride diffusion and chloride migration in self-compacting cementitious composites and the results showed that only minor variations were introduced through the presence of fibres. In another recent study, Frazão et al. [74 also investigated the penetration of chlorides by migration tests according to LNEC E463 [75] and found analogous results. However, based on the significant amount of corrosion caused to the 
steel fibres during the migration tests, the authors concluded that migration tests might not be adequate to determine the resistance of SFRC to chloride ingress. They argued that steel fibres could act as a preferential location for chlorides to settle, thus preventing their advance towards deeper zones. However, migration tests could present an additional drawback. The parameters under which the test is performed, i.e. the voltage applied and the duration of the test, are based on the initial measurements of the electric current when a certain potential is applied. If conductive fibres are added to concrete, these could influence the initial current and consequently the test parameters. Although both parameters are considered in the equation used to calculate the migration coefficient, this may still potentially skew the results from migration tests. A summary of the results found in the literature regarding the determination of the chloride diffusion coefficients of SFRC is presented in Fig. 6] as normalized diffusion coefficients of SFRC against plain concrete diffusion coefficients. Note that the coefficient of variation of reproducibility of the tests used to determine the data presented in Fig. 6is commonly around $15 \%$, indicating that the differences observed are generally not significant.

\subsection{Resistivity}

The electrical resistivity of a material describes its ability to withstand the transfer of charge. The resistivity of concrete principally depends on three factors: (i) the degree of saturation, being the most important; (ii) the pore network (including the degree of porosity, pore volume, distribution and connectivity) which is affected by parameters such as the $w / c$ ratio, maturity or admixtures; and (iii) the pore solution characteristics (presence of ions such as chlorides) 3. Thus, depending on the environmental conditions and the concrete quality, the resistivity of concrete may vary between values in the order of a few tens of $\Omega \cdot m$ to many thousands of $\Omega \cdot m[76$. Since corrosion is an electrochemical phenomenon, the electrical resistivity of concrete will influence the corrosion rate of the embedded steel as an electrical current, in the form of charged ions, needs to flow between the anode and the cathode for corrosion to occur [2].

There is a considerable amount of work available in the literature on results that indicate the great importance of resistivity as a parameter to describe the corrosion rate in reinforced concrete structures.
For instance, Alonso et al. 77 monitored the corrosion rate and electrical resistance values of reinforcing bars embedded in mortars made of six different types of cement, which were exposed to varying moisture conditions. They noted that electrical resistivity appeared to be the factor controlling the maximum corrosion rate in aerated specimens. Morris et al. [78] aimed at establishing a corrosion evaluation criterion based on concrete electrical resistivity measurements. They stated that concrete resistivity can be used as a parameter to evaluate the risk of rebar corrosion regardless of mix design and environmental exposure conditions. A literature review of research concerning the relationship between the electrical resistivity of concrete and the corrosion rate of embedded reinforcement by Hornbostel et al. is available in [79. In that study, despite a distinct correlation could be observed between the corrosion rate and the concrete resistivity, the scatter found in the reported experimental data was large, indicating that other factors such as the cement type or the cause of corrosion may influence significantly the relationship.

Resistivity is a material property and, as such, it is not dependent on the specimen geometry or the electrode configuration. Resistivity is, however, determined from electrical resistance tests. The electrical resistance, $R$, is given by Ohm's law:

$$
R=\frac{V}{I}
$$

where $V$ is the potential and $I$ is current. In order to obtain the resistivity, $\rho$, the electrical resistance must be corrected to account for the specimen size and electrode configuration, which is usually done by introducing a parameter, $k$, known as geometry factor or cell constant, as shown in Eq. (4) [80]:

$$
\rho=k \cdot R
$$

Although a wide variety of techniques have been used in the past, currently, there are two widely spread methods to measure the resistivity of concrete: surface and uniaxial tests, see Fig. 7. The use of Direct current (DC) or Alternate current (AC) measurements has also been a subject of discussion. Today, AC measurements are preferred to DC measurements due to problems regarding electrode polarization and spatial variation of the concrete properties over time, associated with ion migration [81. Despite the concrete response to an AC electric field is known to be dependent on the excitation 


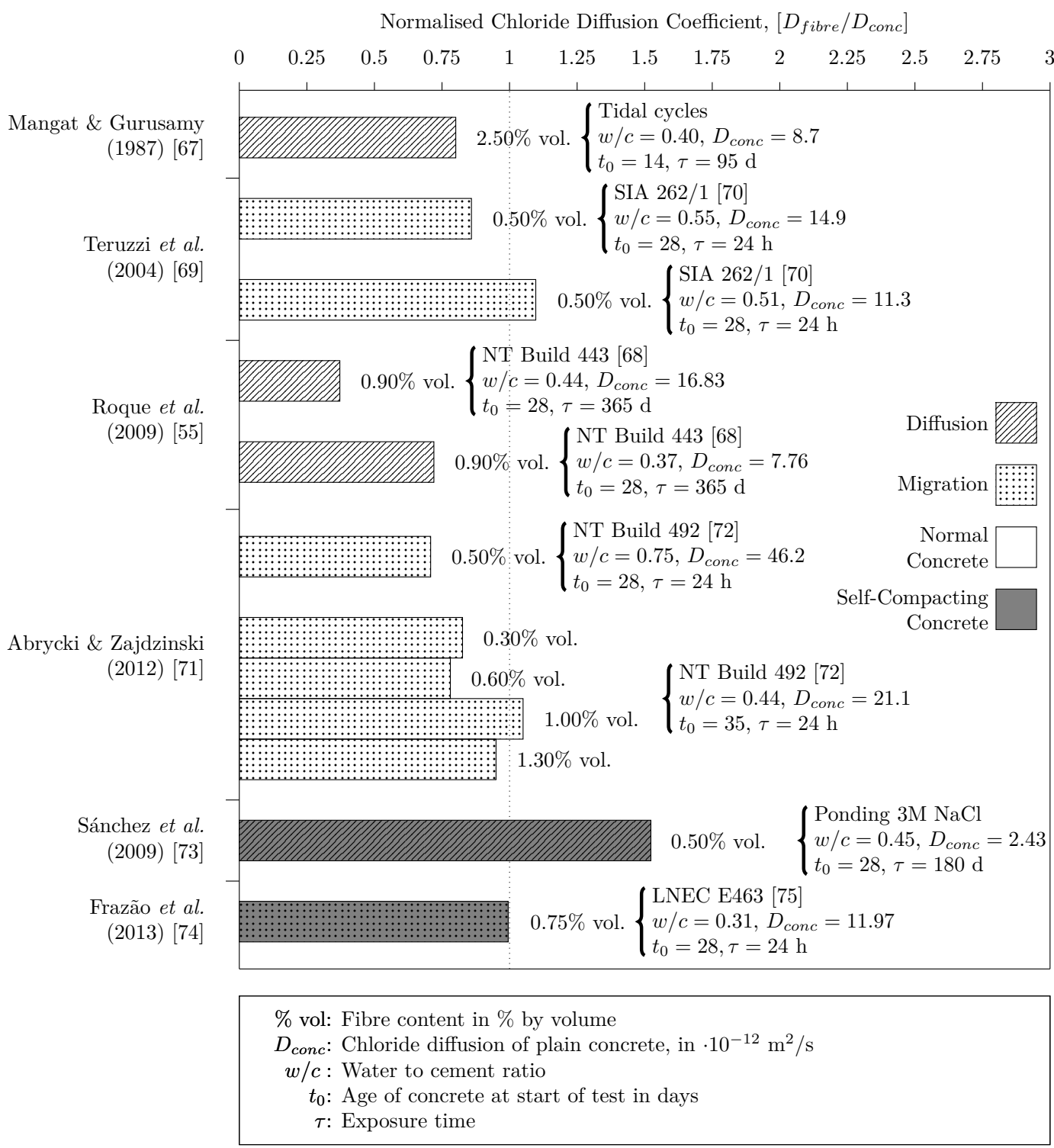

Figure 6: Reported chloride diffusion coefficients of SFRC normalized against plain concrete diffusion coefficients.

frequency, $f$, it has been observed that for low frequencies, up to $1000 \mathrm{~Hz}$, the measured impedance, $Z$, corresponds approximately to the DC resistance $R$ [82. Consequently, the resistance, $R$, can be replaced by the impedance, $Z$, in Eq. (3) and Eq. (4) to calculate the electrical resistivity.

Although experimental data on the resistivity of SFRC are not as numerous as the equivalent data for $\mathrm{RC}$, in the last decade, several researchers have reported experimental observations regarding the influence of steel fibres on the resistivity of concrete. Roque et al. [55] performed surface resistiv- ity tests for two types of concrete with different $w / c$ ratios; Abrycki and Zajdzinski [71] carried out uniaxial resistivity tests for concrete specimens with varying fibre dosages ranging from $0.3 \%$ to $1.3 \%$ by volume; Frazão et al. [74] used a Wenner resistivimeter to assess the electrical resistivity of selfcompacting FRC specimens; Tsai et al. 83 performed resistivity tests on specimens made of selfcompacting concrete with pozzolanic additions for different fibre dosages while Nili and Afroughsabet 84] studied the influence of steel fibres and silicafume additions on the resistivity of concrete. 

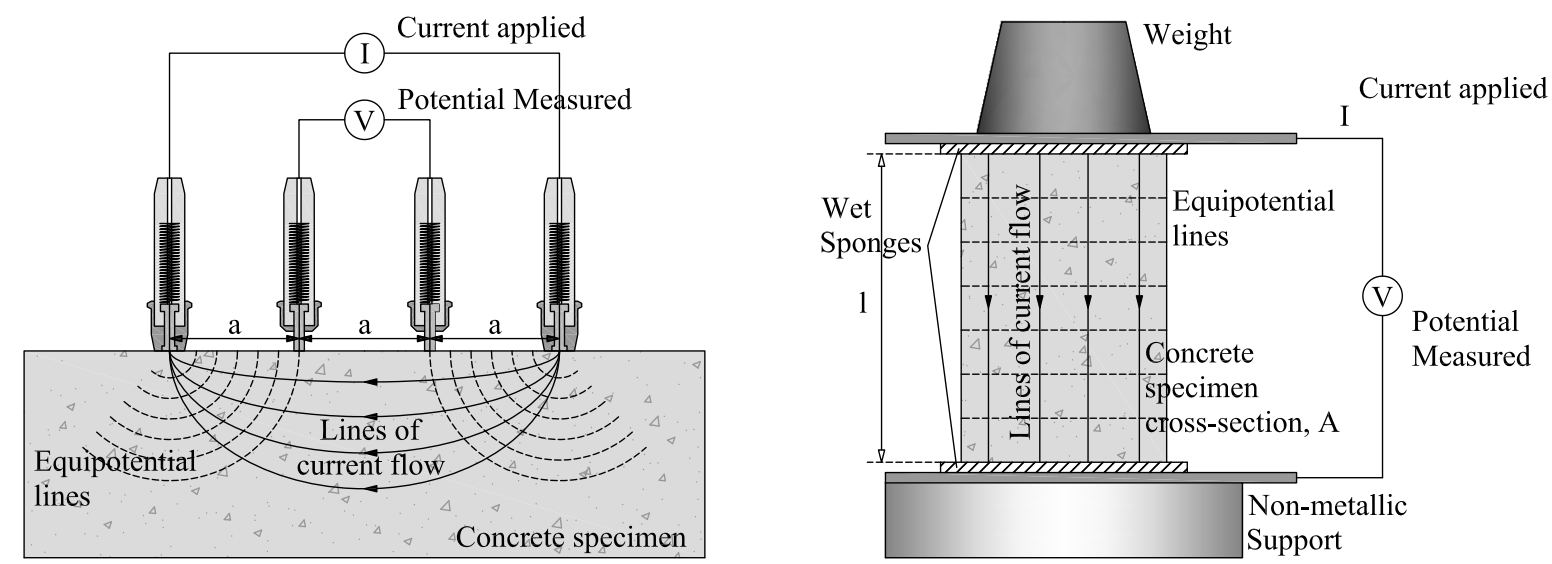

Figure 7: Working principle of commonly used electrical resistance tests

The results from these investigations coincided on concluding that the addition of conductive fibres causes a significant drop in the concrete resistivity due to the conductivity of fibres when compared to plain concrete; this will happen independently of the concrete mix composition. Besides, the results also show a marked tendency for the resistivity to decrease with increasing fibre volume. This finding can be observed in Fig. 8, where the resistivity of SFRC has been normalized by the resistivity of plain concrete; the reduction of resistivity, in \%, is plotted as a function of the fibre volume for saturated specimens. Solgaard et al. [85] also studied the influence of fibre length on resistivity and found out that the scatter was larger for longer fibres which was attributed to the higher probability to creating bridge connections between fibres. Grubb et al. 86 investigated the effect of steel micro-fibres on the corrosion of steel reinforcing bars and measured lower electrolytic resistance for steel fibre reinforced mortars. However, the corrosion rate, based on polarization resistance and Tafel slope measurements, indicated that steel micro-fibre reinforced mortars were more resistant to corrosion than control mortars. They argued that in cement based materials, the electric current travels via ionic flow, whereas in steel fibre reinforced composites, the electric current will also travel via electron transfer within the fibres. In other words, they concluded that steel fibres would affect the measured resistivity whereas the ionic flow, which is the relevant factor for corrosion, would remain constant and, consequently, the correlation between corrosion rate and resistivity should not be applied to concrete materials with steel fibre reinforcement.

In a study by Erdélyi et al. [87, the impact of the moisture condition on the resistivity of concrete was investigated. While the resistivity of plain concrete increased by several orders of magnitude when the measurements were performed in dry conditions compared to satured concrete, only a limited increase was observed in the resistivity of SFRC. They concluded that the overall susceptibility of SFRC structures would increase due to the lower electrical resistivity caused by the presence of steel fibres and, therefore, the inner zones of the structures should be kept dry as much as possible. Similar results were found in a study by Solgaard et al. [81, in which experiments were carried out to quantify the impact of the fibre volume fraction and moisture content on the electrical resistivity of SFRC. Although the moisture content seemed to have a much higher impact on the resistivity, the tendency of the resistivity to decrease with an increasing amount of fibres was also observed for lower degrees of saturation. The influence of the degree of saturation was, however, lower for SFRC. The authors concluded that fibres would decrease the resistivity of concrete when applying AC at 126 $\mathrm{Hz}$, but this represented a conservative estimate of the impact of steel fibres on the electrical resistivity. They argued that fibres embedded in concrete are usually electrically insulated at DC owing to the presence of the passive layer formed in the highly alkaline conditions provided by the concrete pore solution.

This behaviour had previously been described 


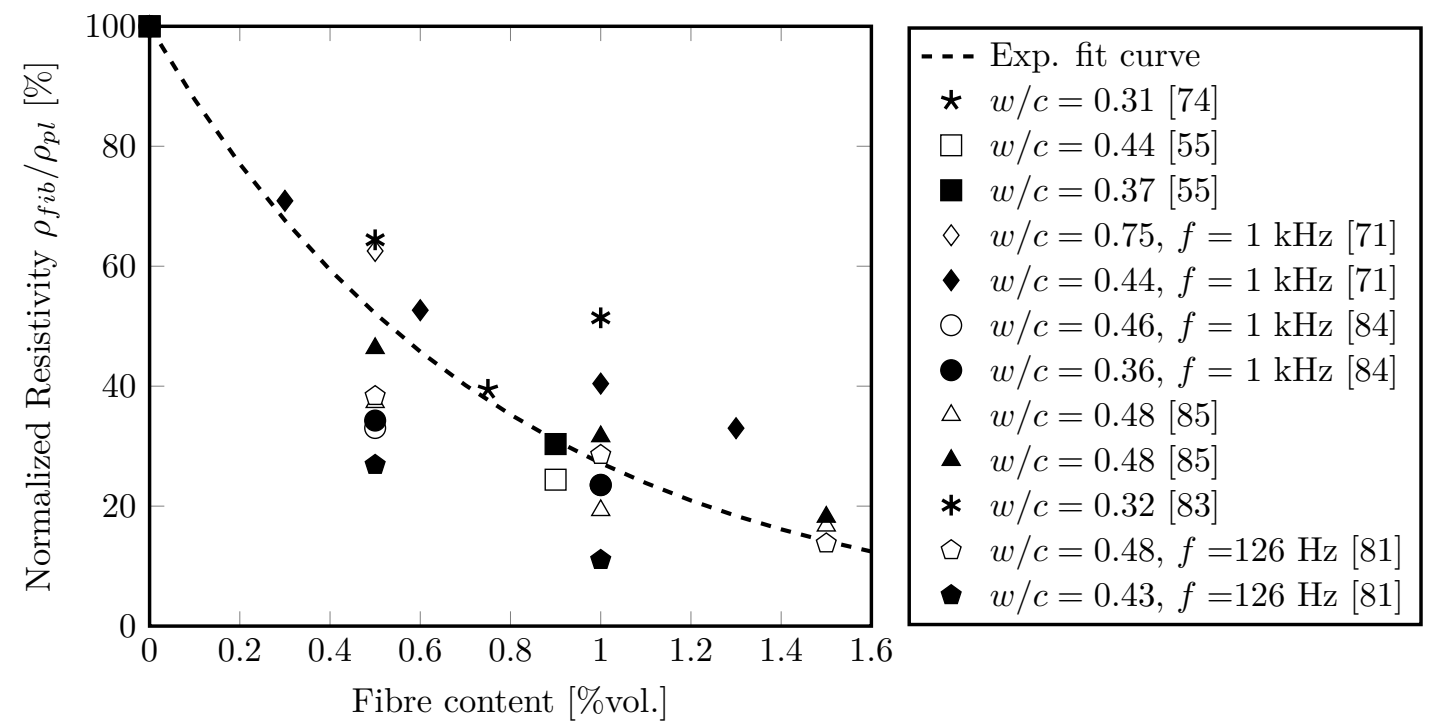

Figure 8: Normalized resistivity of steel fibre reinforced concrete to resistivity of plain concrete as a function of the fibre content. Experimental results from AC measurements. Excitation frequency is included when available in the references.

by Torrents et al. 88,89 and Mason et al. 90] who studied the impedance spectra of fibrereinforced cement-based composites. They carried out impedance measurements over the frequency range of $0.1 \mathrm{~Hz}$ to $10 \mathrm{MHz}$ and analysed the frequency response in Nyquist plots. They concluded that the addition of conductive fibres to cementbased composites would have a negligible influence on the DC electrical resistance or low frequency response, but they would play a dominant role in the intermediate and high frequency AC response. They attributed this behaviour to the existence of high impedance polarization layers (double layers and/or oxide films) on the surface of the fibres, which insulate the fibres under DC or low AC frequencies but can be shorted out under high $\mathrm{AC}$ frequency excitation. Hixson et al. [91] studied the Current-Voltage $(I-V)$ non-linear response of steel fibre reinforced cement composites and applied increasing intensities of DC to destabilise the oxide coating by driving the electrochemical reactions into the active or transpassive corrosion regimes. They observed that the two $I-V$ slopes for low and high DC fields, corresponded to the low and high excitation frequency resistances under AC, respectively. It must be noted that while for plain concrete the impedance under excitation frequencies up to $1000 \mathrm{~Hz}$ correlates well to the DC electrical resistance, for the same range of frequencies steel fibres will be conductive, resulting in lower mea- sured resistivity. For steel fibre reinforced cement composites the range of frequencies corresponding to the DC resistance may be significantly lower, of the order of just a few $\mathrm{Hz}$, cf. [91. This fact indicates that common methods used to measure resistivity of plain concrete, based on AC measurements, should be adjusted to correctly assess the electrical resistance of steel fibre reinforced cement composites. On the other hand, the voltage threshold needed to short out the passive oxide film seemed to increase with decreasing fibre length according to the findings by Hixson et al. 91. In line with these results, in a study about the risk of stray current circulation in SFRC, Solgaard et al. 92] quantified the potential gradient necessary for stray current to circulate through the fibres in about 10-13 $\mathrm{V} / \mathrm{m}$, for a favourable position of the fibres aligned with the direction of the current, but it was found to be one order of magnitude lower for reinforcing bars featuring a length ten times greater. Although these findings suggest that fibres will most likely remain insulated by the passive layer, there are studies which indicate that the passive film formed on the surface of carbon steel can behave both as an insulator and as an n-type semiconductor, and this is still a subject of controversy, as discussed in [93]. Moreover, despite possessing an increased corrosion resistance, steel fibres placed at the concrete cover, and specially bridging cracks, can actively corrode and thus become conductive. 


\section{Chloride induced corrosion of steel fibres}

Despite the fact that the principles governing corrosion in conventionally reinforced concrete are equally applicable to steel fibre reinforced concrete, the results from several investigations, see e.g. [28, 94, 95], suggest that steel fibres have an improved corrosion resistance compared to conventional reinforcing steel.

For fibre concrete, some of the fibres will inevitably lie at the concrete surface with minute, almost negligible, cover depths. Intuitively, these fibres should be especially susceptible to external agents, and consequently, high degradation would be expected when exposed to aggressive environments. This has been confirmed and reported by several researchers, where fibres located in depths of only a few millimetres presented signs of corrosion, or even severe corrosion, whereas the rest of the fibres, i.e. those fully embedded inside the concrete, remained free of corrosion, see e.g. 30, 31, 96, 97, 98, 99]. Besides, it has also been reported that corrosion of superficial fibres is commonly accompanied by extensive rust stains appearing at the concrete surface, which can be noted, in some cases, at early ages of exposure, e.g. 97, 100. This may pose an impediment to the use of steel fibres in concrete elements expected to remain visible during their service lives. However, in a study by Balouch et al. [30, it was found that decreasing the water cement ratio of the concrete mix can effectively reduce the extent of damage in the fibres, as well as limiting the region where fibres are prone to suffer severe corrosion at depths as small as $0.2 \mathrm{~mm}$. Although other factors, such as the aggressiveness of the environment or the exposure time, can influence the depth at which fibres are readily corroded, available data indicate that this depth is generally smaller than $10 \mathrm{~mm}$ even for lengthy exposures, as shown in Table 1, where reported values on depths at which fibres are affected by corrosion are summarized.

In some cases the corrosion resistance of steel fibres has been indirectly evaluated in terms of a reduction in the structural performance of the concrete specimens investigated. Accordingly, steel fibre reinforcement has been attributed an increased corrosion resistance due to the absence of adverse effects on the structural integrity after a period of exposure to a corrosive environment, as reported by several authors, e.g. [95, 98, 102, 103, 104. Ordinary carbon-steel fibres, however, tend to cor- rode when cracks develop on the surface. A critical crack width, below which corrosion of fibres passing through the cracks is prevented, has been mentioned in a number of investigations. Apparently, this critical crack width is strongly dependent on the type of fibre used.

Mangat and Gurusamy [105] carried out an experimental programme to evaluate the long-term marine durability of SFRC in cracked and uncracked concrete specimens. They used two types of fibres: low carbon and melt-extract (stainless) steel fibres; marine conditions were simulated using sea-water spray in a curing chamber where specimens were subjected to two wet and two dry cycles every 24 hours. After 450 days, they found that pitting corrosion was initiated in low carbon steel and melt-extract steel fibres bridging cracks of a width greater than 0.24 and $0.94 \mathrm{~mm}$, respectively. Nemegeer et al. [106] induced 0.2 and $0.5 \mathrm{~mm}$ wide cracks in a wedge splitting test on $100 \mathrm{~mm}$ cube specimens made of FRC with low-carbon and zinccoated steel fibres and exposed them to different environments. After 18 months, they found that the maximum corrosion depth on the fibres was 16 $\mu \mathrm{m}$ locally and determined that crack widths up to $0.5 \mathrm{~mm}$ would not have an adverse effect on corrosion. Similar results are reported by Granju and Balouch [84], who pre-cracked specimens measuring $100 \times 100 \times 500 \mathrm{~mm}$ in a three-point bending setup to obtain a crack mouth opening of $0.5 \mathrm{~mm}$. After a year of exposure to an aggressive marine-like environment they reloaded the specimens to evaluate their peak load and post-crack carrying capacity and observed that those specimens the cracks of which were kept open during the exposure period presented a uniform gain in strength in the peak and post-peak stages. They argued that the most likely explanation for this behaviour was the increased bond between the fibres and concrete matrix due to the light corrosion observed on the surface of the fibres.

Results from other investigations showed, however, that crack bridging fibres suffering from severe corrosion can lead to an important loss of the SFRC mechanical properties. In a study by Bernard [107], the author investigated the role of crack width in controlling the rate of corrosion of steel fibre reinforced shotcrete (SFRS). Using precracked round panels according to ASTM C-1550, it was observed that after only seven months of exposure to a coastal environment there was substantial loss of performance for panels with crack widths 
Table 1: Reported values on concrete depths where fibres are affected by corrosion

\begin{tabular}{|c|c|c|c|c|}
\hline Reference & $\begin{array}{c}\text { Concrete } \\
\text { Depth } \\
{[\mathrm{mm}]}\end{array}$ & $w / c$ & Ambient & Exposure time \\
\hline Rider et al., cited in [29] & 6.4 & 0.60 & $\begin{array}{l}\text { Sea water flow apparatus to } \\
\text { half-immersed specimens }\end{array}$ & 6 months \\
\hline Lankard et al., cited in [29] & 1.6 & 0.46 & $\begin{array}{l}\text { Weekly application of } 0.2 \\
\mathrm{~kg} / \mathrm{m}^{2} \text { of } \mathrm{NaCl}\end{array}$ & 5 years \\
\hline Aitcin et al., cited in [29] & 3.2 & 0.44 & $\begin{array}{l}\text { Salt fog cabinet with } 5 \% \mathrm{CaCl}_{2} \\
\text { salt solution }\end{array}$ & 67 days \\
\hline Hanant et al., cited in 29$]$ & 6.4 & 0.75 & $\begin{array}{l}\text { Combined exposure at Surrey } \\
\text { University / coastal ambient }\end{array}$ & $245 / 325$ days \\
\hline Balouch et al. 30 & 1 & 0.78 & $\begin{array}{l}\text { Weekly cyclic exposure to a fog } \\
\text { chamber with } 35 \mathrm{~g} / 1 \mathrm{NaCl}\end{array}$ & 7 months \\
\hline Granju et al. 96 & 3 & 0.60 & $\begin{array}{l}\text { Weekly cyclic exposure to a fog } \\
\text { chamber with } 3.5 \mathrm{~g} / 1 \mathrm{NaCl}\end{array}$ & 12 months \\
\hline Serna et al. 100 & 2 & 0.50 & $\begin{array}{l}\text { Wetting-drying cycles in artifi- } \\
\text { cial sea water }\end{array}$ & 12 months \\
\hline Corinaldesi et al. [101] & 2 & 0.40 & $\begin{array}{l}10 \% \mathrm{NaCl} \text { aqueous solution ex- } \\
\text { posure }\end{array}$ & 130 days \\
\hline
\end{tabular}

above $0.1 \mathrm{~mm}$. Nordström [108] also investigated the corrosion durability of sprayed concrete specimens containing steel fibres. A combination of field exposure tests and laboratory tests was used to assess the loss of residual strength and fibre diameter reduction among other parameters. Field exposure tests included cracked beams with crack widths ranging between 0.1 and $1 \mathrm{~mm}$ exposed to three different environments: a motorway, a river side and a tunnel, all of them located in Sweden. The results showed that an initial increase in the residual strength could be expected, principally for crack widths below $0.5 \mathrm{~mm}$. After five years, however, this trend had already changed and reductions of up to $30 \%$ of the initial strength were observed. Nordström attributed the early increase of strength to the progress of the cement hydration whereas crack self-healing was found to be the most reasonable cause for the lower degradation in specimens with smaller crack width. The results from the laboratory tests revealed that longer fibres suffered higher corrosion rates and that wider cracks yielded larger loss of fibre diameter.

Kosa and Naaman [109] and Kosa et al. [110, investigated the extent of fibre corrosion and its effects on the reduction of strength and toughness of SFRC. Specimens of two different dimensions, $75 \times 12.5 \times 300 \mathrm{~mm}$ and $75 \times 37.5 \times 450 \mathrm{~mm}$, were precracked in a four-point bending setup and exposed to wetting-drying cycles of salt solutions for two, six and nine months before re-testing their bending capacity. The results showed a decrease in strength and toughness with increasing exposure times which they attributed to a reduction of fibre diameter. Moreover, they noted that fibres gradually changed their failure mode from typical pullout to fibre breakage. This fact is in agreement with the findings by Serna and Arango [100], who also studied the corrosion behaviour of cracked SFRC specimens using a variety of fibres, including lowcarbon and zinc-coated steel fibres with different aspect ratios. Their results showed that the decrease in mechanical performance was proportional to the time of exposure to an artificial seawater solution and to crack width. In all cases, except for the zinc-coated fibres, an embrittlement of the flexural behaviour was observed.

Fibres fully embedded in concrete will, nevertheless, remain free of corrosion despite concrete being completely saturated by chlorides. This may indicate that the critical chloride content, which is generally accepted to be in the range of $0.4-1.0 \%$ $\mathrm{Cl}^{-}$(by weight of cement) for conventionally reinforced concrete structures, is significantly higher for steel fibres. Raupach et al. 28] set out to evaluate the critical chloride content of three differently shaped fibres (crimped, end-hooked and straight) with a similar chemical composition. Using cor- 
rosion potential and polarization resistance measurements, they determined that fibres possessed a critical chloride value of between $2.1-4.7 \% \mathrm{Cl}^{-}$ (by weight of cement). This value is in agreement with the results reported by Nemegeer et al. 106 and Mangat and Gurusamy 67, 111, who found no signs of corrosion in fibres embedded in concrete with chloride contents of $2.11 \%$ and $2.4 \%$ (by weight of cement), respectively. Dauberschmidt and Raupach [112, who studied the passivation and depassivation process of steel fibres in artificial pore solution and chloride contaminated concrete, also attributed the improved chloride resistance of fibres to a more homogeneous and less reactive passive layer compared to conventional reinforcing bars.

According to Dauberschmidt [113, and in line with the findings of Angst et al. [48, the increased corrosion resistance of steel fibres is caused by a combination of factors: a) the short length of the steel fibres, which impedes large potential differences along the fibre and thus limits the formation of distinct anode and cathode regions; and b) the casting conditions (floating in the concrete matrix as opposed to bar reinforcement) which allow for the formation of a very thin well-defined concretesteel interfacial layer rich in $\mathrm{Ca}(\mathrm{OH})_{2}$ without the presence of voids at the interface as is common for ordinary reinforcement.

\section{Corrosion of steel bars in SFRC}

Despite the increased utilization of steel fibres and the fact that fibres have already been successfully used as structural reinforcement in precast pre-stressed beams or tunnel lining segments, steel fibres cannot today replace the conventional reinforcing bars in most civil engineering structures. Therefore, fibres are in many cases only used as complementary reinforcement. However, the simultaneous use of steel fibres and conventional reinforcing steel in chloride environments generates concerns that steel fibres might be accelerating the corrosion process of reinforcing bars, thereby shortening the life span of the structure. In order to discern whether any potential risks exist or, conversely, steel fibres might contribute to improve the overall durability performance of RC structures, some researchers have directed their investigations towards this particular topic during the last few years. In the following section, a description of the experimental investigations to study the corrosion process of steel reinforcing bars in SFRC is presented, together with the most relevant findings and the conclusions by the authors. Subsequently, the results are analysed and discussed.

\subsection{Experimental investigations}

Someh and Saeki 114 tried to combine the improved mechanical properties of SFRC with the cathodic protection provided by zinc to steel by adding zinc-coated steel fibres to concrete. Based on previous experience, they argued that galvanized fibres would act as numerous sacrificial anodes protecting the main reinforcing bars. They exposed $100 \times 100 \times 400 \mathrm{~mm}$ beam specimens to 12 -hour wet and 12-hour dry cycles in a $5 \% \mathrm{NaCl}$ solution. Their results showed that steel bars embedded in concrete with $1.5 \%$ vol. zinc-coated fibres remained free of corrosion for a period of six months while bars embedded in plain concrete exhibited generalized pitting corrosion after three months. This occurred despite the fact that the chloride concentration was clearly higher in the former case. The authors attributed it to a higher capacity of fibres to adsorb chloride and form quasi-stable ferrous and ferric oxychlorides. Grubb et al. 86] investigated the effect of steel micro-fibres on the corrosion of steel reinforcing bars. They used two different $w / c$ ratios of 0.40 and 0.55 and a fibre dosage of $4.5 \%$ vol. to cast $\varnothing 75 \times 150 \mathrm{~mm}$ cylindrical specimens with one steel bar in the centre, with and without fibres. They subjected the specimens to continuous immersion in a $3.5 \% \mathrm{NaCl}$ air-pumped aerated solution and performed several electrochemical tests, including corrosion potentials, polarization tests and impedance measurements, to monitor the rebar corrosion state. Their measurements indicated that steel micro-fibre reinforced mortar had better corrosion resistance than plain mortar. They suggested that the formation of a passive layer for steel in a cement based matrix is an oxygen intensive process and, therefore, the extensive amount of surface provided by the addition of steel micro-fibres might act as localized sinks to draw oxygen away from the steel reinforcing bar. Nevertheless, they concluded that the mechanisms causing reduced corrosion rates in the micro-fibre reinforced specimens could not yet be clearly identified and required further investigation.

In a series of tests reported by Kobayakawa et al. 115, the authors investigated the influence of two different types of fibre reinforcement, namely polyethylene (PE) fibres and a blend of PE and steel 
fibres, on corrosion of conventional reinforcement. Beam specimens, made using these fibres and also made of plain mortar and reinforced by a single steel bar, were exposed to wet-dry cycles in a $3 \% \mathrm{NaCl}$ solution while corrosion was further promoted during wetting periods through an impressed current using a DC power device to impose a $3 \mathrm{~V}$ potential difference. The amount of corrosion estimated based on the current measurements using Faraday's law showed that PE fibres improved the corrosion resistance with respect to plain mortar and that a further improvement was achieved by adding steel fibres. The difference in the current measurements of the three mixes was mainly attributed to the corrosion-induced damage observed on the specimens: a localized crack parallel to the steel bar in the plain mortar; a somewhat narrower crack in PE reinforced mortar specimens; and no visible surface cracks in the mix with steel fibres. Although large overestimations of the corrosion rates were obtained in the current measurements for the concrete containing steel fibres, which the authors attributed to the interference of steel fibres, actual corrosion measurements, by weight loss of steel, confirmed this trend. More recently, Mihashi et al. [116] further discussed the results from the same series of tests. They recovered the idea by Someh and Saeki [114 and reasoned that due to the random distribution of fibres within the concrete, some fibres might be interconnected in the cover zone to touch the reinforcing bar. Because of their connectivity to the steel bar, the anodic region in their setup could be extended to the steel fibres and their proximity to the cathodic region (an external wire mesh) could turn fibres into sacrificial anodes. They also argued that for natural corrosion, due to the early presence of oxygen and aggressive agents like chlorides, the passivity of fibres would first break down. Those fibres in contact with steel reinforcement would become anodes, thus reducing the corrosion in the steel bar. In those fibres which were not in contact with the steel reinforcing bar, the corrosion rate could be expected to be minor due to the improved resistance of the fibres.

This concept was evaluated in a study carried out by Matsumoto et al. [117. On the assumption that steel fibres can effectively reduce the amount of corrosion of reinforcing bars, their experiments aimed at establishing a durability evaluation method to identify the mechanisms for reduced corrosion. They used beam specimens measuring $100 \times 100 \times 400 \mathrm{~mm}$ and a reinforcing bar placed with a clear concrete cover of $25 \mathrm{~mm}$. Three different types of specimen were cast: plain concrete, SFRC and plain concrete specimens in which a 15 $\mathrm{mm}$ layer at the cover was replaced by SFRC. After undergoing 95 cycles of three days wetting a in $10 \% \mathrm{NaCl}$ solution and four days of air-drying, a visual inspection revealed that plain concrete specimens exhibited longitudinal cracks ranging between 0.05 and $0.15 \mathrm{~mm}$ whereas specimens with fibres in the cover only exhibited both longitudinal and transversal cracks ranging between 0.1 and 0.5 mm. Specimens with fibres throughout their full depth, however, presented no cracking at the surface. Based on the ratio between the corroded and total surface of the steel bars, the results from the reinforcement corrosion state showed that the corrosion was more extensive in specimens with wider cracks, i.e. those with fibres in the cover only, while a minor improvement was achieved for SFRC specimens compared to plain concrete specimens. Half-cell potential measurements showed a similar behaviour independently of the presence of fibres. They concluded that a small corrosion suppression effect might happen when using SFRC but its effectiveness is conditioned on the absence of surface cracking. When corrosion-induced cracks appear, the corrosion rate can rapidly increase to values similar to those of plain concrete.

Maalej et al. 118 introduced the concept of Functionally-Graded Concrete (FGC) beams where the bottom part of the cross-section of a beam is cast with a ductile fibre reinforced cementitious composite (DFRCC) whereas the remainder is filled with plain concrete. The main differences are the composition of the DFRCC material, a blend of $1 \%$ steel and 1.5\% PVA fibres exhibiting strain hardening behaviour and multiple cracking and the fact that, in this concept, the tensile reinforcement is fully embedded into the DFRCC section. Using a similar setup to promote corrosion as the one described by Kobayakawa et al. [115], the authors used medium-scale beam specimens, including compression and shear reinforcement to test the effectiveness of DFRCC in retarding the corrosion of steel reinforcement. In total five beams were fabricated, two of them using plain concrete whereas the remaining three were FGC beams. One specimen of each type was kept for control purposes and the rest, prior to undergoing accelerated corrosion, were subjected to three cycles of four-point bending up to $70 \%$ of the ultimate load. After unloading, the maximum crack widths measured $0.19 \mathrm{~mm}$ for 
plain concrete and 0.12 to $0.13 \mathrm{~mm}$ for FGC. Two of the cracked beams, one for each type, were then subjected to accelerated corrosion for 83 days until the estimated steel loss reached $10.1 \%$ and $6.6 \%$, respectively. The remaining specimen was left to corrode for a period of 141 days until the estimated steel loss was also 10\%. During the accelerated corrosion process, a crack mapping was performed for the beams, which revealed the formation of several longitudinal and transversal cracks on the plain concrete beam. Although no cracks were detected for the FGC beams, leaching of soft corrosion products were spotted along the interface of the two different concretes. The results of the bending tests upon corrosion showed that the plain concrete beam lost about $13 \%$ of its ultimate load-carrying capacity and $9 \%$ of its deflection capacity compared to the control specimen, accompanied by local spalling upon failure. Similarly, although no spalling was observed, the FGC with $10 \%$ estimated steel loss showed a decrease in both peak load and deflection of $11 \%$ and $6 \%$, respectively. Visual examination of steel bars showed that corrosion was uniformly distributed in the plain concrete beam with few corrosion pits on both the longitudinal and transverse reinforcement. On the other hand, the FGC beam presented minimum signs of corrosion except for the central part where pre-cracks of larger width were located. Also in the stirrups, local pitting corrosion was detected at the interface between the concrete and the DFRCC material. Maalej et al. determined that steel loss calculations based on Faraday's law, usually giving overestimation for reinforcement embedded in concrete, further overestimate the actual amount of steel loss in FGC which, based on the findings by Auyeung et al. [119, were attributed to an enhanced water tightness and better chloride ingress resistance. Overall, the authors concluded that FGC beams were effective in delaying the corrosion process and in preventing corrosion induced damage with associated concrete delamination and spalling.

Kim et al. [120] studied the influence of various types of fibre on transport mechanisms in concrete and used a steel reinforcement corrosion testing in accordance with ASTM G-109a [121] to evaluate the effect of fibres on resistance to corrosion of steel bars embedded in FRC. They tested PVA, Polypropylene (PP) and steel fibres and found that the steel fibres presented the best performance in terms of reduced water permeability and chloride diffusion. However, despite current measurements indicating that steel fibres had no significant effect on the corrosion rate subsequent to the initiation of corrosion, reinforcement corrosion tests showed that corrosion was initiated significantly earlier in SFRC specimens than in plain concrete. Based on the highly degraded aspect offered by the SFRC specimens, showing severe corrosion of fibres and surface spalling, the authors argued that a possible cause for the early onset of corrosion might be attributable to a higher mass movement of chloride ions into the concrete due to micro-cracking caused by the severely corroded steel fibres. Nevertheless, they concluded that the mechanisms affecting corrosion of embedded reinforcement in FRC are not yet fully understood and that further study will be required to isolate the effect of potential fibre mechanisms.

Excluding minor geometry modifications of the specimens, Ostertag and Blunt [122] used the same corrosion test setup as defined in [121] to examine the effect of crack control, achieved by using a hybrid fibre reinforced concrete (HyFRC) made of steel macro-fibres and PVA micro-fibres, on the corrosion rate of steel reinforcing bars. A total of six specimens, three made of plain concrete and three made of HyFRC, were cast. Prior to the exposure to cyclic ponding with a $3 \% \mathrm{NaCl}$ solution, specimens were subjected to five cycles of loading with a four-point bending setup to a load chosen to maximize the crack width without exceeding the yield strength of the rebar, which was kept constant between the two types of specimen to compare their behaviours based on load demands. As a result, all plain concrete specimens showed one or two transverse cracks ranging from 0.3 to $0.4 \mathrm{~mm}$ wide, as well as some longitudinal cracks ranging between 0.07 and $0.1 \mathrm{~mm}$, whereas no cracks were detected in HyFRC specimens. Current measurements indicated a significant difference in the corrosion rates of almost one order of magnitude over the monitoring period. After nine months of chloride exposure, the mechanical performance was assessed by a monotonic four-point bending test up to failure. Results showed that, for the plain concrete specimens, the yield load of the rebar was below the load used in the pre-cracking test suggesting that a significant amount of corrosion had occurred. For the HyFRC specimens, however, the yielding point was far above the load mentioned. Chloride content analyses were also performed and contrary to what the authors had anticipated, the chloride content in the plain concrete was significantly higher than for 
HyFRC even where the cores had been taken sufficiently far from the cracks to represent an uncompromised matrix. They found that a possible explanation for this effect might be attributed to the internal cracking from bond stresses, mainly dependent on the geometry and load of the rebar and the quality and thickness of the surrounding concrete. The authors argued that the presence of fibres in the HyFRC would help to resisting this cracking mechanism in two different ways: (i) first, it would reduce the load demand on the rebar by carrying part of the stresses and (ii) in the case of crack formation, the presence of fibres would provide a source of toughening in the matrix, thereby reducing the crack propagation. In the light of their results, they concluded that the crack resisting characteristics of the HyFRC influenced the corrosion rate by slowing the rate of chloride ingress.

Similar results were found by Mihashi et al. [123. who used the same specimen configuration, materials and test setup described in the experiments by Kobayakawa et al. [115] to extend the investigation of the effect of fibres on the corrosion of steel reinforcement bars to cracked specimens. Thus, several specimens were cracked at various crack widths ranging between 0 and $0.6 \mathrm{~mm}$ and subjected to accelerated corrosion for a year. During this period, the width of corrosion-induced cracks was monitored. Specimens containing steel fibres showed higher performance after having arrested corrosioninduced cracks, which was reflected in the lower corrosion rates measured compared to the other mixes. Among the specimens of the same mix, a correlation was also found between the initial crack width and the corrosion rate, except for plain concrete specimens. After a year of accelerated corrosion, reinforcing bars were retrieved and cleaned from rust and corrosion products to assess their actual loss of steel by gravimetric methods. Maximum corrosion depths were also measured before performing a uni-axial tensile test to determine the residual ultimate tensile strength. A clear trend was observed for maximum corrosion depths to increase and for residual tensile strength to decrease with increasing initial crack widths. The results consistently showed an improved behaviour for fibre reinforced specimens, attributed by the authors to a superior crack-bridging capacity.

Niş et al. 124 also studied the influence of steel fibres on the corrosion of reinforcing bars on cracked concrete specimens subjected to different types of loading. They used two $w / c$ ratios, 0.45 and 0.65 , to prepare beam elements with $100 \times 100 \times 400 \mathrm{~mm}$ dimensions. Ribbed $\varnothing 14 \mathrm{~mm}$ bars were used as longitudinal reinforcement and two concrete covers of 25 and $45 \mathrm{~mm}$ were studied. Half of the specimens were made of plain concrete and the other half had a fibre content of $0.5 \%$ by volume. After 28 days of curing, one third of the beams were kept as control specimens and the remainder were loaded to induce cracking. Targeted crack widths were chosen to keep a constant ratio between crack width and concrete cover, i.e. $0.4 \mathrm{~mm}$ cracks for a $45 \mathrm{~mm}$ cover and $0.22 \mathrm{~mm}$ cracks for a $25 \mathrm{~mm}$ cover. Moreover, two loading conditions were used, static loading and cycles of dynamic loading with a load range of between $10 \%$ of the theoretical failure load and the load reached to induce the aimed crack width. Corrosion was promoted by cyclic ponding using a solution of $35 \mathrm{~g} / \mathrm{l}$ of $\mathrm{NaCl}$. A device based on the galvanostatic pulse technique was used to monitor the corrosion potential and corrosion rate. After 47 wet-dry cycles, the results showed a good correlation between potential and current measurements, i.e. lower potentials were usually associated with higher corrosion rates. In uncracked specimens, the $w / c$ ratio was identified as the most important factor whereas the effect of the steel fibres and the concrete cover was insignificant. In the cracked beams, despite measurements indicating that corrosion had proceeded at a higher rate, the $w / c$ ratio remained the parameter playing a major role and it was only in the dynamically loaded beams that the steel fibre reinforced specimens showed a significant improvement with respect to their plain concrete counterparts. The authors concluded that steel fibres can provide a positive effect in corrosion protection when the crack development is a critical issue.

\subsection{Discussion}

Fig. 9 and Fig. 10 show the steel loss (in terms of uniform corrosion depths) as a function of time for all experimental investigations reviewed that reported measurements of the corrosion rate of reinforcing bars embedded in SFRC. Fig. 9 shows the measurements from specimens that were subjected to accelerated corrosion under uncracked conditions while Fig. 10 shows the measurements from specimens that were previously loaded to promote cracking. It must be noted that the ordinate axis scale differs in several orders of magnitude between the different plots. 


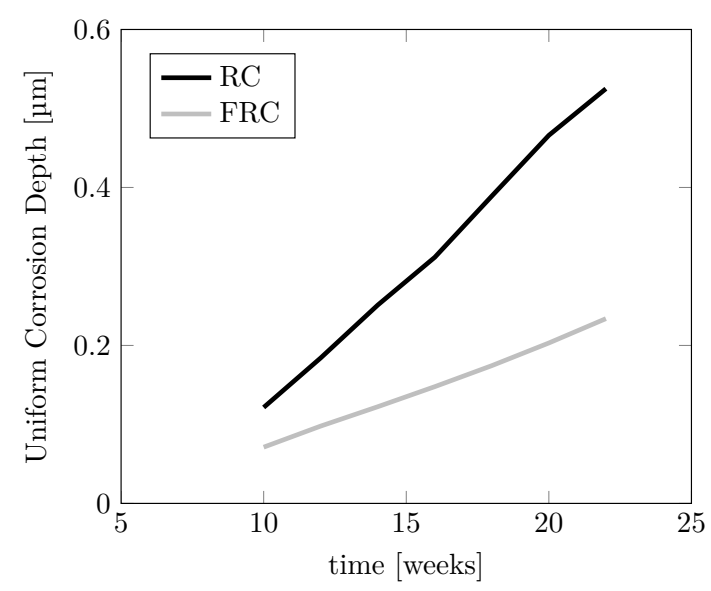

(a) Immersion in $3.5 \% \mathrm{NaCl}$ solution, from 86

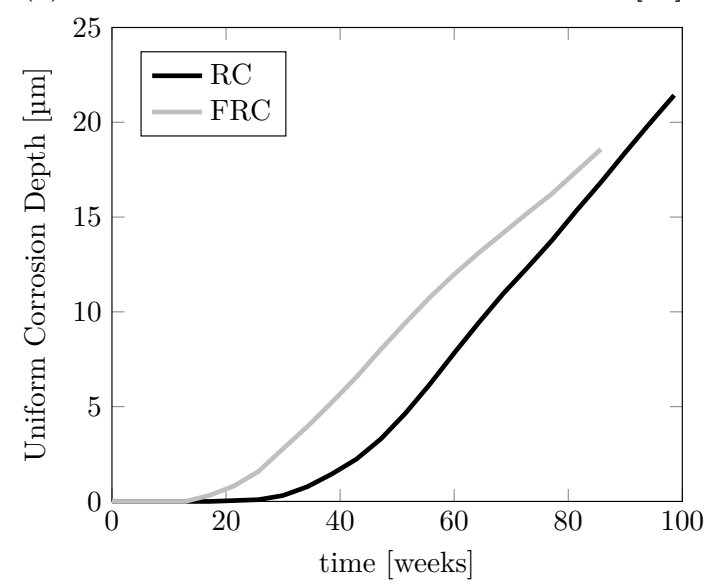

(b) Cyclic ponding with $16.5 \% \mathrm{NaCl}$ solution, from 120

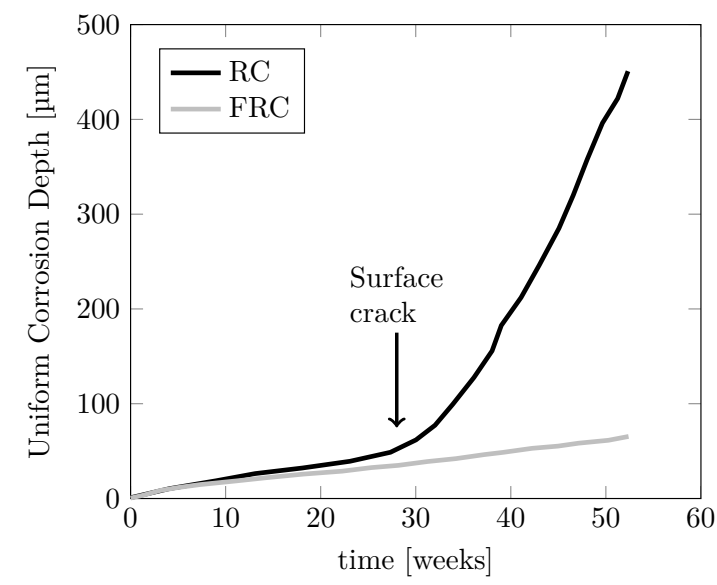

(c) Cyclic damping in $3.0 \% \mathrm{NaCl}$ solution with impressed current [3V DC], from [115]

Figure 9: Steel loss calculations based on Faraday's law from current measurements, represented as uniform corrosion depth in $[\mu \mathrm{m}]$. Uncracked concrete specimens

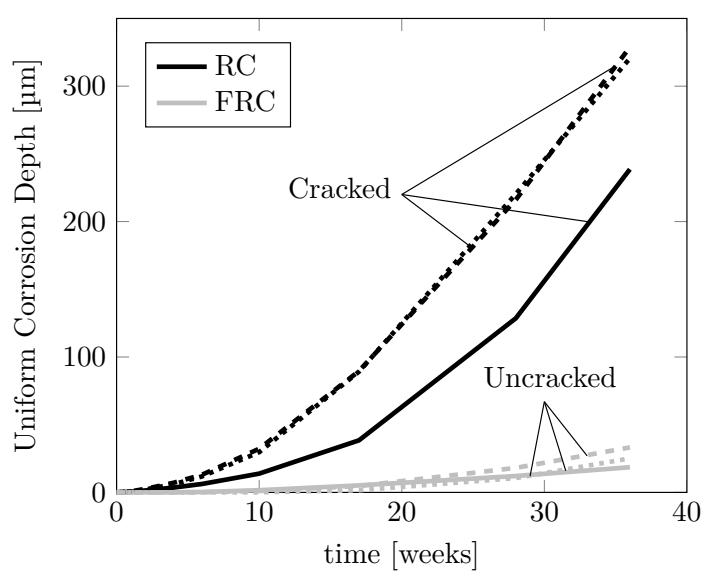

(a) Cyclic ponding with $3.0 \% \mathrm{NaCl}$ solution, from 122

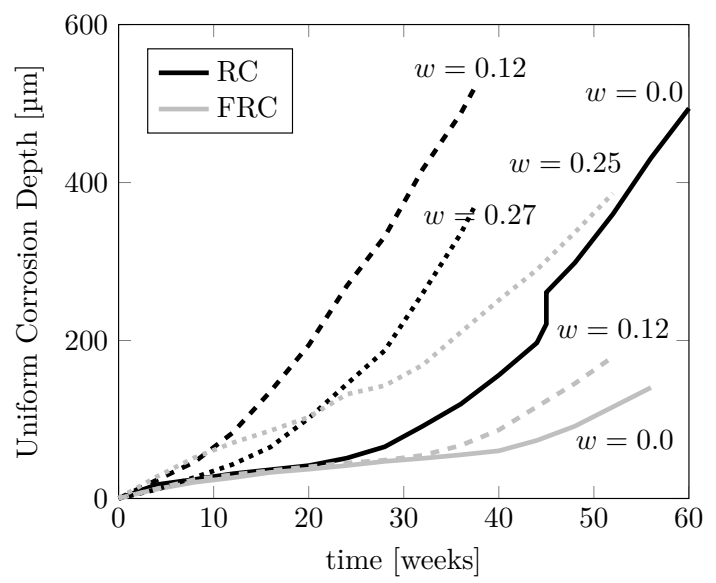

(b) Cyclic damping in $3.0 \% \mathrm{NaCl}$ solution with impressed current [3V DC], from [123]

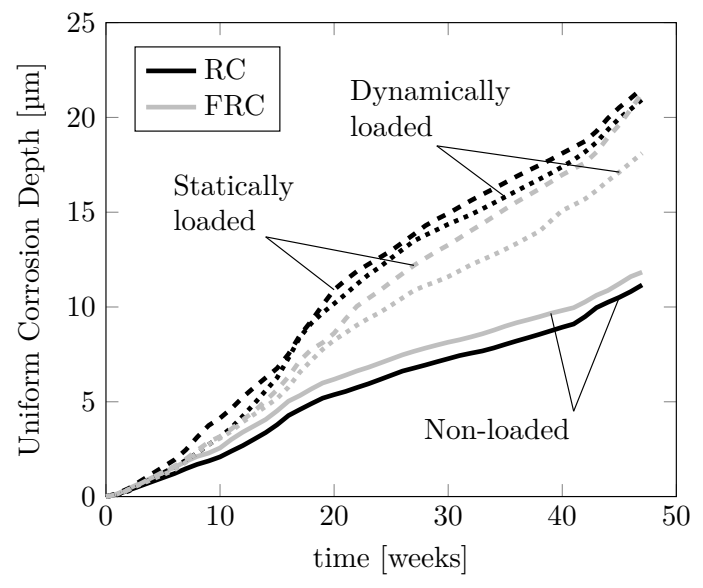

(c) Cyclic ponding with $3.5 \% \mathrm{NaCl}$ solution, from 124

Figure 10: Steel loss calculations based on Faraday's law from current measurements, represented as uniform corrosion depth in $[\mu \mathrm{m}]$. Cracked concrete specimens 
In reviewing Fig. 9, it is noted that experimental observations of different investigations yield inconsistent results. In Fig. 9a and Fig. 9c fibres seem to have a beneficial effect, although in the first case the measured corrosion rate is so small that the difference is insignificant. In the second case, the change in slope for the plain concrete specimen coincided, according to the authors, with the formation of a longitudinal surface crack, whereas no cracks were observed for the FRC specimen during the total duration of the test. Fig. 9b, on the other hand, indicates that fibres might accelerate the corrosion process; the corrosion initiation in particular takes place earlier while the corrosion rate showed similar values as those measured for plain concrete. The authors reported that steel fibres suffered severe corrosion which might have led to internal micro-cracking and to subsequent increase of chloride ingress.

In the case of measurements performed on precracked specimens, the results from Fig. 10 tend to show a beneficial effect of steel fibres on the corrosion of the embedded steel bar. In Fig. 10a, the remarkable improvement observed is at least partially due to the fact that all specimens were subjected to the same load level and, while plain specimens developed surface macro-cracking, no cracking was detected on fibre reinforced specimens. These results are not relevant to study the direct impact that steel fibres might have the on corrosion of reinforcement but offer a good example of how fibres, by controlling cracking, can positively affect the durability of structures. Results from Fig. $10 \mathrm{~b}$ are, perhaps, the ones showing a clearer improvement on the corrosion behaviour of the rebar which may be attributed to fibres. Despite displaying similar initial surface crack widths, fibre reinforced specimens consistently show a lower steel loss. According to the authors, this is caused by the ability of the fibres to arrest crack propagation and prevent cracks to further widen due to the expansive nature of the corrosion products. Finally, Fig. 10c shows that steel fibres had little effect on uncracked and statically loaded specimens whereas a minute improvement can be noticed for dynamically loaded beams. Again, the authors concluded that the beneficial effects of fibres will be noticed when crack propagation becomes a critical issue.

From these results, it might be inferred that steel fibres themselves do not significantly affect the corrosion process of steel reinforcing bars embedded in concrete. However, they can delay and reduce the degradation of reinforcement by means of crackcontrol mechanisms. If we think of the total life span of a reinforced concrete structure, it can be divided, in corrosion terms, into two periods of time: initiation and propagation 11. This is schematically illustrated in Fig. 11. The initiation period is considered to be the time required by the external aggressive agents to penetrate into the concrete and cause the depassivation of the reinforcing steel. During the propagation period, the steel reinforcement corrodes and the expansive nature of the corrosion products causes tensile stresses that can originate cracking and spalling of the concrete cover, thus increasing the corrosion rate and reducing the safety of the structure.

In light of the results here presented, it is hypothesized that the addition of fibres, by controlling the growth of cracks formed in the initiation phase or corrosion-induced cracks in the propagation phase, can provide an effective protection against corrosion of steel bars in reinforced concrete structures. This hypothesis is also illustrated in Fig. 11, where the initiation period is extended due to the arrest of early cracks caused by, for example, shrinkage, temperature gradients or external loads. Similarly, during the propagation period corrosion induced damage is delayed, thus keeping lower corrosion rates and postponing the end of the service life of a structure. However, another less favourable scenario is also possible. Considering a reduced electrical resistivity, characteristic of cementitious matrices containing steel fibres in a conductive state, e.g. when they are corroding, it is arguable whether the corrosion rate of embedded reinforcement will remain at low values or whether the corrosion will proceed at a faster rate. In that case, even if the onset of corrosion is delayed due to better crack control at early stages, the steel loss could be accelerated once the corrosion has initiated, thus hastening the end of the structure service life of the structure.

It is noteworthy that in the case of SFRC, regardless of the rate at which corrosion proceeds, the fact that fibres, given that a sufficient quantity has been added, prevent the degradation of concrete, in terms of corrosion-induced cracking and spalling, also means that fibres hide the full extent of the damage caused by corrosion. This, together with the early rust stains often found in SFRC structures exposed to chloride environments, would mean that criteria based on visual observation of a structure are no longer valid in terms of evaluating the corrosion state and plan potential repair 
actions. Furthermore, results from some investigations reporting gross overestimations of the steel loss using calculations based on Faraday's law from accelerated corrosion test in which an externally impressed current was applied, e.g. 115, 118 suggest that existing current-based techniques might not be suitable to adequately monitor the corrosion state of reinforcement embedded in SFRC. Based on what has been discussed in Section 3.3 any technique in which a relatively high DC field or high $\mathrm{AC}$ frequency is applied, might change the state of steel fibres in concrete from insulated to conductive, thus potentially yielding misleading results. Consequently, there is a need for more experimental data to assess the adequacy of current-based techniques, used e.g. to monitor corrosion, originally intended for plain concrete, when steel fibres are added.

Additionally, some investigations mention that steel fibres formed a galvanic cell and acted as sacrificial anodes to protect the conventional reinforcing bar. To the authors' knowledge, this effect has not been studied in order to find out under what conditions galvanic corrosion is feasible, the extent of galvanic corrosion and whether the galvanic cell might act in the opposite direction, i.e. accelerating the corrosion of conventional reinforcement.

Nevertheless, considering the limited amount of existing research investigations on this subject and the short duration of the experiments carried out so far, it is difficult to affirm with certainty whether or not steel fibres may prolong the service life of RC structures by providing corrosion protection.

\section{Conclusions and need for further research}

This paper aims at determining the viability of using steel fibres in combination with traditional steel reinforcing bars in chloride environments as a way of improving the durability of reinforced concrete structures. Through a review of the existing literature, a study of durability aspects of SFRC has been presented. The concluding remarks derived from this study are summarized in the following:

1. SFRC commonly shows strain hardening and multi-cracking behaviour when high fibre dosages ( $>2 \%$ by vol.) are used. In RC structures, a reduction of the crack separation and crack width can be achieved for lower fibre dosages. Additionally, fibre reinforcement has proven to decrease the extent of damage at the steel-concrete interface (slip and separation), which has been suggested as a more reliable indicator of the risk of corrosion initiation.

2. As a result of the correlation between crack width and permeation, fibre reinforced concrete exhibits improved water tightness in a cracked state compared to plain concrete.

3. Based on the experimental observations reviewed, the addition of fibres do not significantly influence the chloride diffusion coefficient in uncracked concrete.

4. Although a significant number of investigations have reported that electrical resistivity will decrease when steel fibres are added to the concrete, there are studies supporting that steel fibres will be insulated under DC due to the formation of a high impedance passive layer. This indicates that the range of $\mathrm{AC}$ excitation frequencies commonly used to measure electrical resistivity in plain concrete, should be adjusted to determine the DC resistance of steel fibre reinforced concrete.

5. Passive fibres are considered to be insulated as long as the passive layer is intact, but they will become conductive if corrosion initiates, resulting in a decreased concrete resistivity. Although the corrosion of fibres is generally limited to the fibres located at the surface or bridging cracks, the effect of a decreased resistivity caused by the presence of conductive fibres on the corrosion rate of rebar has not been investigated. However, it has been hypothesized that conductive fibres will not necessarily influence the corrosion rate as these will not modify the ionic flow within the concrete, which is the relevant factor for corrosion.

6. Steel fibres have been found to have a higher corrosion resistance than conventional reinforcement. Nevertheless, low carbon steel fibres located near the surface or bridging the cracks can be severely corroded, showing conspicuous rust stains and in some cases causing localized damage to the concrete. Embedded fibres, however, have proven to remain free of corrosion despite high chloride contents.

7. Experimental results suggest that steel fibres per se have minor influence on the corrosion rate of reinforcement. On the other hand, some beneficial effects can be observed in cracked concrete specimens, where the improvements are mainly attributed to a lower ingress of chloride due to reduced crack widths. This can 


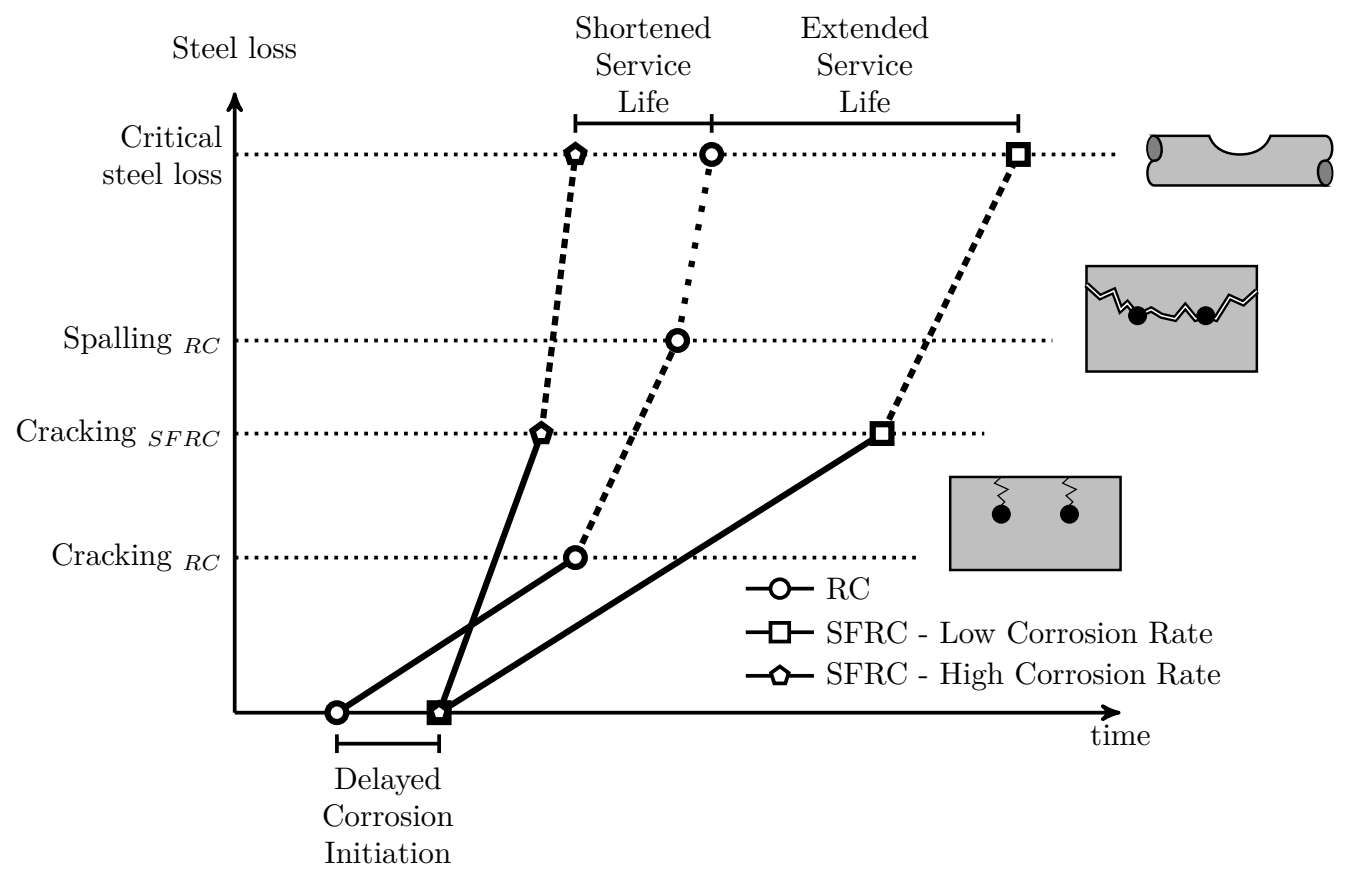

Figure 11: Hypothetical scenarios showing the effect of steel fibres on degradation of reinforced concrete structures, adapted from 10 10. Note that the presented model assumes initially cracked concrete.

also be observed in uncracked specimens where fibres might arrest the development of bond stress micro-cracks.

Despite steel fibres could potentially contribute to decrease the corrosion of reinforced concrete structures, the impact on the corrosion rate of reinforcing bars and the risk of galvanic corrosion between the fibres and the bars when the fibres are conductive, i.e. corroding, have not been specifically addressed. Therefore, more experimental work is needed to quantify the potential influence of steel fibres on the corrosion process of conventional reinforcement.

\section{References}

[1] K. Tuutti, Corrosion of steel in concrete, CBI Report 4:82, The Swedish Cement and Cocnrete Institute. (1982) 468.

[2] J. Broomfield, Corrosion of steel in concrete: understanding, investigation and repair, 2nd Edition, Taylor \& Francis, Abingdon, United Kingdom, 2002.

[3] L. Bertolini, B. Elsener, P. Pedeferri, R. Polder, Corrosion of Steel in Concrete. Prevention, Diagnosis, Repair., Wiley-VCH Verlag GmbH \& Co. KGaA, Weinheim, Germany, 2004

[4] M. Montemor, A. Simões, M. Ferreira, Chlorideinduced corrosion on reinforcing steel: from the fundamentals to the monitoring techniques, Cement and
Concrete Composites 25 (4-5) (2003) 491-502. doi: 10.1016/S0958-9465(02) 00089-6

[5] U. M. Angst, B. Elsener, C. K. Larsen, O. Vennesland, Chloride induced reinforcement corrosion: Electrochemical monitoring of initiation stage and chloride threshold values, Corrosion Science 53 (4) (2011) 1451-1464. doi:10.1016/j.corsci.2011.01.025

[6] E. Stansbury, R. Buchanan, Fundamentals of electrochemical corrosion, ASM International, Ohio, USA, 2000.

[7] K. Wang, D. C. Jansen, S. P. Shah, A. F. Karr, Permeability study of cracked concrete, Cement and Concrete Research 27 (3) (1997) 381-393. doi:10.1016/ S0008-8846(97) 00031-8

[8] C. M. Aldea, S. Shah, A. Karr, Permeability of cracked concrete, Materials and Structures 32 (June) (1999) 370-376.

[9] C. Edvardsen, Water Permeability and Autogenous Healing of Cracks in Concrete, ACI materials Journal $96(4)$.

[10] fib Model Code for Concrete Structures, Vol. 14, Wiley-VCH Verlag GmbH \& Co. KGaA, Weinheim, Germany, 2010. doi:10.1002/9783433604090

[11] EN 1992-1-1 Eurocode 2, EN 1992-1-1 Eurocode 2: Design of concrete structures - Part 1-1: General rules and rules for buildings (2004).

[12] A. W. Beeby, Cracking: what are crack width limits for?, Concrete 12 (7) (1978) 31-33.

[13] C. Andrade, A. Muñoz, A. Torres-Acosta, Relation between crack width and corrosion degree in corroding elements exposed to the natural atmosphere, framcos.org (2010) 853-858.

[14] T. Vidal, A. Castel, R. François, Analyzing crack 
width to predict corrosion in reinforced concrete, Cement and Concrete Research 34 (1) (2004) 165-174. doi:10.1016/S0008-8846(03)00246-1

[15] S. Yoon, K. Wang, W. Weiss, S. Shah, Interaction between loading, corrosion, and serviceability of reinforced concrete, ACI materials journal 97 (6) (2000) 637-644.

[16] T. E. Maaddawy, K. Soudki, T. Topper, Long-term performance of corrosion-damaged reinforced concrete beams, ACI Structural Journal 102 (5) (2005) 649656.

[17] P. Schiessl, M. Raupach, Laboratory Studies and Calculations on the Influence of Crack Width on ChlorideInduced Corrosion of Steel in Concrete, ACI Materials Journal 94 (1) (1997) 56-61.

[18] T. U. Mohammed, N. Otsuki, M. Hisada, T. Shibata, Effect of Crack Width and Bar Types on Corrosionof Steel in Concrete, Journal of Materials in Civil Engineering 13 (3) (2001) 194-201. doi:10.1061/(ASCE) 0899-1561(2001) 13:3(194).

[19] S. J. Jaffer, C. M. Hansson, Chloride-induced corrosion products of steel in cracked-concrete subjected to different loading conditions, Cement and Concrete Research 39 (2) (2009) 116-125. doi:10.1016/j. cemconres.2008.11.001

[20] M. Otieno, M. Alexander, H.-D. Beushausen, Corrosion in cracked and uncracked concrete - influence of crack width, concrete quality and crack reopening, Magazine of Concrete Research 62 (6) (2010) 393-404. doi:10.1680/macr.2010.62.6.393

[21] M. Otieno, M. Alexander, H.-D. Beushausen, Corrosion propagation in cracked and uncracked concrete, in: M. Alexander, H.-D. Beushausen, F. Dehn, P. Moyo (Eds.), Concrete Repair , Rehabilitation and Retrofitting II, Taylor \& Francis Group, London, UK, 2009, pp. 339-344.

[22] W. Tian, P. Schiessl, Corrosion Process in Cracked Reinforced Concrete, in: K. Van Breugel, G. Ye, Y. Yuan (Eds.), 2nd International Symposium on Service Life Design for Infrastructure, no. October, Delft, The Netherlands, 2010, pp. 585-602.

[23] J. Pacheco, R. Polder, Advances in Modeling Concrete Service Life, Springer Netherlands, Dordrecht, 2012. doi:10.1007/978-94-007-2703-8

[24] A. M. Brandt, Fibre reinforced cement-based (FRC) composites after over 40 years of development in building and civil engineering, Composite Structures 86 (13) (2008) 3-9. doi:10.1016/j.compstruct.2008.03. 006

[25] C. Johnston, Steel fibre-reinforced concrete-present and future in engineering construction, Composites (April) (1982) 113-121.

[26] A. Bentur, S. Mindess, Fibre reinforced cementitious composites, 2nd Edition, Taylor \& Francis, Abingdon, United Kingdom, 2007.

[27] I. Löfgren, Fibre-reinforced concrete for industrial construction - a fracture mechanics approach to material testing and structural analysis, Ph.D. thesis, Chalmers University of Technology (2005).

[28] M. Raupach, C. Dauberschmidt, T. Eichler, Corrosion Behaviour of Steel Fibres in Concrete Containing Chlorides, in: EUROCORR 2004 - European Corrosion Conference, Long Term Prediction and Modelling of Corrosion, Nice, 12-15 September, 2004.

[29] G. Hoff, Durability of fiber reinforced concrete in a severe marine environment, ACI Special Publication 100 (1987) 997-1042. doi:10.14359/2034

[30] S. U. Balouch, J. P. Forth, J. L. Granju, Surface corrosion of steel fibre reinforced concrete, Cement and Concrete Research 40 (3) (2010) 410-414. doi: 10.1016/j.cemconres.2009.10.001

[31] P. S. Mangat, K. Gurusamy, Long term properties under marine exposure of steel fibre reinforced concrete containing pfa, Materials and Structures 21 (1988) $352-358$.

32] J. P. Romualdi, J. A. Mandel, Tensile Strength of concrete Affected by Uniformly Distributed and Closely Spaced Short Lengths of wire Reinforcement, ACI Journal Proceedings 61 (6) (1964) 657-672. doi: 10.14359/7801

[33] A. E. Naaman, H. W. Reinhardt, Proposed classification of HPFRC composites based on their tensile response, Materials and Structures 39 (5) (2006) 547555. doi:10.1617/s11527-006-9103-2

[34] A. P. Fantilli, H. Mihashi, P. Vallini, Crack profile in $\mathrm{RC}, \mathrm{R} / \mathrm{FRCC}$ and R/HPFRCC members in tension, Materials and Structures 40 (10) (2007) 1099-1114. doi:10.1617/s11527-006-9208-7.

[35] H. H. Abrishami, D. Mitchell, Influence of steel fibers on tension stiffening, ACI Structural Journal 94 (6) (1997) 769-776.

[36] H. Aoude, W. Cook, D. Mitchell, Tensile behaviour of reinforced concrete specimens constructed with steel fibers and SCC, in: 7th RILEM International Symposium on Fibre Reinforced Concrete: Design and Applications - BEFIB 2008, 2008, pp. 689-697.

[37] K. Noghabai, Behavior of Tie Elements of Plain and Fibrous Concrete and Varying Cross Sections, ACI Structural Journal 97 (2) (2000) 277-285. doi:10. 14359/857.

[38] J. Deluce, S. Lee, F. J. Vecchio, Crack Formation in FRC Structural Elements Containing Conventional Reinforcement, in: A. Parra-Montesinos, GustavoJ. and Reinhardt, HansW. and Naaman (Ed.), High Performance Fiber Reinforced Cement Composites 6, Vol. 2 - RILEM State of the Art Reports, 2012, pp. 271278. doi:10.1007/978-94-007-2436-5】_33

[39] F. Minelli, G. Tiberti, G. A. Plizzari, Durability and Crack control in FRC RC elements : an experimental study, in: International RILEM Conference on Advances in Construction Materials Through Science and Engineering, Hong Kong, China, 2011, pp. 435-443.

[40] D. M. Moreno, W. Trono, G. Jen, C. Ostertag, S. L. Billington, Tension stiffening in reinforced high performance fiber reinforced cement-based composites, Cement and Concrete Composites 50 (2014) 36-46. doi:10.1016/j.cemconcomp.2014.03.004

[41] G. Fischer, V. C. Li, Influence of Matrix Ductility on Tension-Stiffening Behavior of Steel Reinforced Engineered Cementitious Composites (ECC), ACI Structural Journal 99 (1). doi:10.14359/11041

[42] A. Jansson, I. Lofgren, K. Lundgren, K. Gylltoft, Bond of reinforcement in self-compacting steel-fibrereinforced concrete, Magazine of Concrete Research 64 (7) (2012) 617-630. doi:10.1680/macr.11.00091

[43] L. H. Lárusson, Development of Flexible Link Slabs using Ductile Fiber Reinforced Concrete, Ph.D. thesis, Technical University of Denmark (2013).

[44] K. Otsuka, H. Mihashi, M. Kiyota, S. Mori, A. Kawamata, Observation of Multiple Cracking in Hybrid 
FRCC at Micro and Meso Levels, Journal of Advanced Concrete Technology 1 (3) (2003) 291-298. doi:10.3151/jact.1.291.

[45] C. Arya, F. Ofori-Darko, Influence of crack frequency on reinforcement corrosion in concrete, Cement and Concrete Research 26 (3) (1996) 345-353. doi:10. 1016/S0008-8846(96)85022-8

[46] K. Tammo, A new approach to crack control for reinforced concrete. An investigation of crack widths close to the reinforcement and the correlation to service life, Ph.D. thesis, Lund University, Sweden (2009).

[47] A. Poursaee, C. M. Hansson, The influence of longitudinal cracks on the corrosion protection afforded reinforcing steel in high performance concrete, Cement and Concrete Research 38 (8-9) (2008) 1098-1105. doi:10.1016/j.cemconres.2008.03.018.

[48] U. Angst, A. Rønnquist, B. Elsener, C. K. Larsen, $\varnothing$. Vennesland, Probabilistic considerations on the effect of specimen size on the critical chloride content in reinforced concrete, Corrosion Science 53 (1) (2011) 177-187. doi:10.1016/j.corsci.2010.09.017.

[49] B. Pease, M. Geiker, H. Stang, J. Weiss, The design of an instrumented rebar for assessment of corrosion in cracked reinforced concrete, Materials and Structures 44 (7) (2010) 1259-1271. doi:10.1617/ s11527-010-9698-1.

[50] A. Michel, A. Solgaard, B. Pease, M. Geiker, H. Stang, J. Olesen, Experimental investigation of the relation between damage at the concrete-steel interface and initiation of reinforcement corrosion in plain and fibre reinforced concrete, Corrosion Science 77 (2013) 308-321. doi:10.1016/j.corsci.2013.08.019.

[51] A. Michel, Reinforcement Corrosion : Numerical Simulation and Service Life Prediction, Ph.D. thesis, Technical University of Denmark (2012).

[52] B. Pease, Influence of concrete cracking on ingress and reinforcement corrosion, Ph.D. thesis, Technical University of Denmark (2010).

[53] N. Banthia, Fiber reinforced concrete for sustainable and intelligent infrastructure, in: SBEIDCO - 1st International Conference on Sustainable Built Environment Infrastructures in Developing Countries, Oran, Algeria. October 12-14, 2009, pp. 337-350.

[54] C. Aldea, M. Ghandehari, S. Shah, A. Karr, Estimation of water flow through cracked concrete under load, ACI Materials Journal 97 (5).

[55] R. Roque, N. Kim, B. Kim, G. Lopp, Durability of Fiber-Reinforced Concrete in Florida Environments, Tech. Rep. July, University of FLORIDA, Tallahassee, FL (2009)

[56] A. Singh, D. Singhal, Permeability of Steel Fibre Reinforced Concrete Influence of Fibre Parameters, Procedia Engineering 14 (2011) 2823-2829. doi:10.1016/ j.proeng.2011.07.355

[57] J. Rapoport, C.-M. Aldea, S. P. Shah, B. Ankenman, A. Karr, Permeability of Cracked Steel FiberReinforced Concrete, Journal of Materials in Civil Engineering 14 (4) (2002) 355.

[58] J. P. Charron, E. Denarié, E. Brühwiler, Permeability of ultra high performance fiber reinforced concretes (UHPFRC) under high stresses, Materials and Structures 40 (3) (2006) 269-277. doi:10.1617/ s11527-006-9105-0

[59] M. Lepech, V. C. Li, Water Permeability of Cracked Cementitious Composites, in: 11th International Con- ference on Fracture (ICF11), Paper 4539, Curran Associates, Inc., Turin, Italy, 2005.

[60] M. Tsukamoto, Tightness of Fibre Concrete, Darmstadt Concrete 5 (1990) 215-225.

[61] M. Tsukamoto, J.-D. Wörner, Permeability of Cracked Fibre-Reinforced Concrete, Darmstadt Concrete1 6 (1991) 123-135.

[62] J. S. Lawler, D. Zampini, S. P. Shah, Permeability of Cracked Hybrid Fiber-Reinforced Mortar under Load, ACI materials Journal 99 (4) (2002) 379-385.

[63] J. S. Lawler, D. Zampini, S. P. Shah, Microfiber and Macrofiber Hybrid Fiber-Reinforced Concrete, Journal of Materials in Civil Engineering 17 (5) (2005) 595604. doi:10.1061/(ASCE) 0899-1561(2005) 17:5(595)

[64] H. W. Song, C. H. Lee, K. Y. Ann, Factors influencing chloride transport in concrete structures exposed to marine environments, Cement and Concrete Composites 30 (2) (2008) 113-121. doi:10.1016/j. cemconcomp.2007.09.005

[65] J. Crank, The Mathematics of Diffusion, 2nd Edition, Oxford University Press, London, UK, 1975.

[66] L. O. Nilsson, Prediction models for chloride ingress and corrosion initiation in concrete structures Tech. rep., Chalmers University of Technology, Nordic Mini Seminar \& fib TG 5.5 meeting, Göteborg, May 22-23 (2001).

URL http://www.lu.se/lup/publication/3920794

[67] P. Mangat, K. Gurusamy, Chloride diffusion in steel fibre reinforced marine concrete, Cement and Concrete Research 17 (1987) 385-396.

[68] NT Build 443, North Test BUILD 443 - Accelerated chloride Penetration, Tech. rep. (1995).

[69] T. Teruzzi, E. Cadoni, G. Frigeri, S. Cangiano, G. A. Plizzari, Durability aspects of steel fibre reinforced concrete, in: 6th RILEM Symposium on Fibre-Reinforced Cocnretes (FRC) - BEFIB2004, no. September, Varenna, Italy - September 20-22, 2004, pp. $625-634$.

[70] SIA 262/1:2003 Swiss norm, Concrete Structures Supplementary specifications (2003).

[71] M. Abrycki, A. Zajdzinski, Effect of fibres on corrosion of steel reinforcement - Master of Science Thesis, Tech. rep., Chalmers University of Technology (2012).

[72] NT Build 492, North Test BUILD 492 - Chloride Migration Coefficient from Non-Steady-State Migration Experiments, Tech. rep. (1999).

[73] M. Sanchez, M. Alonso, B. Barragán, Durability performance of Plain and Fiber Reinforced self-compacting concrete, CPI- Concrete Plant International-2 (2009) 62-64.

[74] C. Frazão, A. Camões, J. Barros, D. Gonçalves, Durability of Steel Fiber Reinforced Self-Compacting Concrete, in: 5th International Conference on The Concrete Future, no. May, Covilhã, Portugal, 2013.

[75] LNEC E463, Determination of diffusion of chlorides by migration under non-steady state (2004).

[76] COST509, Corrosion and Protection of Metals in Contact with Concrete, Final report, Tech. rep., R.N. Cox, R. Cigna, O. Vennesland, T. Valente (Eds.), European Commission, Directorate General Science, Research and Development, Brussels, EUR 17608 EN (1997).

[77] C. Alonso, C. Andrade, J. González, Relation between resistivity and corrosion rate of reinforcements in carbonated mortar made with several cement types, Cement and Concrete Research 18 (5) (1988) 687-698. 
doi:10.1016/0008-8846(88)90091-9

[78] W. Morris, A. Vico, M. Vazquez, S. de Sanchez, Corrosion of reinforcing steel evaluated by means of concrete resistivity measurements, Corrosion Science 44 (1) (2002) 81-99. doi:10.1016/S0010-938X (01) 00033-6

[79] K. Hornbostel, C. K. Larsen, M. R. Geiker, Relationship between concrete resistivity and corrosion rate A literature review, Cement and Concrete Composites 39 (2013) 60-72. doi:10.1016/j.cemconcomp. 2013. 03.019

[80] R. Spragg, Y. Bu, K. Snyder, D. Bentz, J. Weiss, Electrical Testing of Cement-Based Materials: Role of Testing Techniques, Sample Conditioning and Accelerated Curing, Tech. rep., Joint Transportation Research Program Purdue University, West Lafayette, IN 47907-2051 (Dec. 2013). doi:10.5703/1288284315230

[81] A. O. S. Solgaard, M. Geiker, C. Edvardsen, A. Küter, Observations on the electrical resistivity of steel fibre reinforced concrete, Materials and Structures 47 (1-2) (2013) 335-350. doi:10.1617/s11527-013-0064-y

[82] D. A. Whiting, M. A. Nagi, Electrical Resistivity of Concrete - A Literature Review, Tech. rep., Portland Cement Association (2003).

[83] C. Tsai, L. Li, C. Chang, C. Hwang, Durability design and application of steel fiber reinforced concrete in Taiwan., Arabian Journal for Science and Engineering 34 (1) (2009) 57-79.

[84] M. Nili, V. Afroughsabet, Property assessment of steel-fibre reinforced concrete made with silica fume, Construction and Building Materials 28 (1) (2012) 664-669. doi:10.1016/j.conbuildmat.2011.10.027

[85] A. Solgaard, A. Michel, H. Stang, M. R. Geiker, Modelling the influence of steel fibres on the electrical resistivity of cementitious composites, in: 3rd International RILEM PhD Student workshop on Modelling the Durability of Reinforced Concrete - University of Minho, no. 1962, Guimarães, Portugal, 2010, pp. 2027.

[86] J. Grubb, J. Blunt, C. Ostertag, T. Devine, Effect of steel microfibers on corrosion of steel reinforcing bars, Cement and Concrete Research 37 (7) (2007) 11151126. doi:10.1016/j.cemconres.2007.04.012

[87] A. Erdélyi, E. Csányi, K. Kopecskó, A. Borosnyói, O. Fenyvesi, Deterioration of steel fibre reinforced concrete by freeze-thaw and de-icing salts, Concrete Structures - Journal of the Hungarian Group of fib 9 (2008) 33-44.

[88] J. Torrents, T. Mason, E. Garboczi, Impedance spectra of fiber-reinforced cement-based composites: a modeling approach, Cement and Concrete Research 30 (4) (2000) 585-592. doi:10.1016/S0008-8846(00) 00211-8

[89] J. M. Torrents, T. O. Mason, A. Peled, S. P. Shah, E. Garboczi, Analysis of the impedance spectra of short conductive fiber-reinforced composites, Journal of Materials Science 36 (2001) 4003-4012.

[90] T. O. Mason, M. A. Campo, A. D. Hixson, L. Y. Woo, Impedance spectroscopy of fiber-reinforced cement composites, Cement and Concrete Composites 24 (5) (2002) 457-465. doi:10.1016/S0958-9465(01) 00077-4

[91] A. Hixson, L. Woo, M. Campo, T. Mason, The origin of nonlinear current-voltage behavior in fiberreinforced cement composites, Cement and Concrete Research 33 (6) (2003) 835-840. doi:10.1016/
S0008-8846(02) 01062-1

[92] A. Solgaard, M. Carsana, M. Geiker, A. Küter, L. Bertolini, Experimental observations of stray current effects on steel fibres embedded in mortar, Corrosion Science 74 (2013) 1-12. doi:10.1016/j.corsci. 2013.03.014

[93] P. Ghods, Multi-Scale Investigation of the Formation and Breakdown of Passive Films on Carbon Steel Rebar in Concrete, Ph.D. thesis, Carleton University (2010).

[94] I. Janotka, L. Krajcí, K. Komlos, D. Frtalová, Chloride corrosion of steel fibre reinforcement in cement mortar, The International Journal of Cement Composites and Lightweight Concrete 11 (4) (1989) 221-228.

[95] H. Sadeghi-pouya, E. Ganjian, P. Claisse, K. Muthuramalingam, Corrosion durability of high performance steel fibre reinforced concrete, in: Third International Conference on Sustainable Construction Materials and Technologies, Kyoto, Japan - August 18-21, 2013.

[96] J. L. Granju, S. Ullah Balouch, Corrosion of steel fibre reinforced concrete from the cracks, Cement and Concrete Research 35 (3) (2005) 572-577. doi:10.1016/ j.cemconres.2004.06.032

[97] L. Ferrara, R. Fratesi, S. Signorini, F. Sonzogni, M. Building, Durability of Steel Fibre-Reinforced Cocnrete Precast Elements: Experiments and Proposal of design recommendations, in: 6th RILEM Symposium on Fibre-Reinforced Cocnretes (FRC) - BEFIB 2004, Varenna, Italy - September 20-22, 2004, pp. 565-574.

[98] A. G. Graeff, K. Pilakoutas, C. Lynsdale, K. Neocleous, Corrosion Durability of Recycled Steel Fibre Reinforced Concrete, "Intersections" international journal 6 (4) (2009) 77-89.

[99] P. Mangat, K. Gurusamy, Long-term properties of steel fibre reinforced marine concrete, Materials and structures 20 (1987) 273-282.

[100] P. Serna, S. E. Arango, Evolution of the Flexural Behaviour of Precracked SFRC in Marine Environment, in: 7th RILEM International Symposium on Fibre Reinforced Concrete: Design and Applications - BEFIB 2008, Chennai, India - September 17-19, 2008, pp. 595-605.

[101] V. Corinaldesi, G. Moriconi, Durable fiber reinforced self-compacting concrete, Cement and Concrete Research 34 (2) (2004) 249-254. doi:10.1016/ j.cemconres.2003.07.005

[102] G. Mantegazza, A. Gatti, Aspects of Durability of Fiber Reinforced Concrete: Workability and StressCorrosion, in: 6th RILEM Symposium on FibreReinforced Cocnretes (FRC) - BEFIB 2004, no. September, Varenna, Italy - September 20-22, 2004, pp. 593-602.

[103] N. Buratti, C. Mazzotti, M. Savoia, Long-Term Behavior of Cracked SFRC Elements Exposed to Chloride Solutions, ACI Special Publication (2011) 1-14.

[104] E. Parant, R. Pierre, F. L. Maou, Durability of a multiscale fibre reinforced cement composite in aggressive environment under service load, Cement and Concrete Research 37 (7) (2007) 1106-1114. doi: 10.1016/j.cemconres.2006.02.021

[105] P. Mangat, K. Gurusamy, Permissible crack widths in steel fibre reinforced marine concrete, Materials and structures (1987) 338-347.

[106] D. Nemegeer, J. Vanbrabant, H. Stang, Brite Euram program on steel fibre concrete. Subtask: Durability 
: corrosion resistance of cracked fibre reinforced concrete., in: International RILEM Workshop on Test and Design Methods for Steelfibre Reinforced Concrete, RILEM Publications SARL, 2003, pp. 47-66. doi:10.1617/2351580168.004

[107] E. Bernard, Durability of cracked fibre reinforced shotcrete, in: Shotcrete: More Engineering Developments: Proceedings of the Second International Conference on Engineering Developments in Shotcrete, Cairns, Queensland, Australia, 2004, pp. 59-66.

[108] E. Nordström, Durability of Sprayed Concrete Steel fibre corrosion in cracks, Ph.D. thesis, LuleåUniversity of Technology (2005).

[109] K. Kosa, A. Naaman, Corrosion of steel fiber reinforced concrete, ACI materials Journal 13 (4) (1990) $239-245$.

[110] K. Kosa, A. E. Naaman, W. Hansen, Durability of Fiber Reinforced Mortar, ACI materials Journal (88M38) (1991) 310-319.

[111] P. Mangat, K. Gurusamy, Corrosion Resistance of Steel Fibres in Concrete under Marine Exposure, Cement and Concrete Research 18 (1988) 44-54.

[112] C. Dauberschmidt, M. Raupach, Passivity and Depassivation of Steel Fibres and Cold-Drawn Steel Wires in Artificial Pore Solution and Concrete Containing Chlorides, in: Proceesings EUROCORR 2005, Lisbon, Portugal - September 4-8, 2005.

[113] C. Dauberschmidt, Untersuchungen zu den Korrosionsmechanismen von Stahlfasern in chloridhaltigem Beton, Ph.D. thesis, Technischen Hochschule Aachen (2006).

[114] A. K. Someh, N. Saeki, The Role of Galvanized Steel Fibers in Corrosion-Protection of Reinforced Concrete, Proceedings of Japan Concrete Institute 19 (1) (1997) 889-894.

[115] A. Kobayakawa, D. Homma, H. Mihashi, K. Shimozawa, Corrosion durability of fiber reinforced cementitious composites, in: Proceedings of the 2nd RILEM workshop on concrete durability and service life planning - ConcreteLife'09, no. 1, Haifa, Israel, 2009, pp. 311-318.

[116] H. Mihashi, S. Faiz, U. Ahmed, A. Kobayakawa, Corrosion of Reinforcing Steel in Fiber Reinforced Cementitious Composites, Journal of Advanced Concrete Technology 9 (2) (2011) 159-167.

[117] J. Matsumoto, K. Horiguchi, T. Maruya, A Study on Durability of Reinforced Concrete using Steel Fibres under the Chloride Attack Condition, in: 8th International Symposium on Fibre Reinfored Concrete: Challenges and Opportunities - BEFIB2012, Guimarães, Portugal, 2012.

[118] M. Maalej, S. F. Ahmed, P. Paramasivam, Corrosion Durability and Structural Response of FunctionallyGraded Concrete Beams, Journal of Advanced Concrete Technology 1 (3) (2003) 307-316. doi:10.3151/ jact.1.307

[119] Y. Auyeung, P. Balaguru, L. Chung, Bond Behavior of Corroded Reinforcement Bars, ACI Materials Journal 97 (2) (2000) 214-221. doi:10.14359/826.

[120] B. Kim, A. J. Boyd, J. Y. Lee, Effect of transport properties of fiber types on steel reinforcement corrosion, Journal of Composite Materials 45 (8) (2010) 949-959. doi:10.1177/0021998310380286

[121] ASTM G109-07, Standard test method for Determining the effects of chemical admixtures on the cor- rosion of embedded steel reinforcement in concrete exposed to chloride environments, Tech. rep. (2007). doi:10.1520/G0109-07R13

[122] C. P. Ostertag, J. Blunt, Effect of crack control in hybrid fiber reinforced concrete composites on corrosion rate of steel reinforcing bars, in: Fracture Mechanics of Concrete and Concrete Structures - Assessment, Durability, Monitoring and Retrofitting of Concrete structures, no. mm, Seoul, Korea Concrete Institute, 2010, pp. 894-900.

[123] H. Mihashi, S. F. U. Ahmed, A. Kobayakawa, Influence of crack widths on corrosion of reinforcing steel bar in fiber reinforced cementitious composites, in: International RILEM Conference on Advances in Construction Materials Through Science and Engineering, Hong Kong, CHina, on 5-7 September, 2011, p. n/a.

[124] A. Niş, T. A. Söylev, A. O. Pehlivan, N. O. Zihnioglu, T. Özturan, Effect of crack opening under cyclic loading on the reinforcement corrosion in concrete with and without steel fiber, in: The European Corrosion Congress, EUROCORR 2012, Istanbul, Turkey, 2012, p. CD. 